\title{
Ergative case, Aspect and Person splits: Two case studies
}

\author{
M. Rita Manzini \\ Università di Firenze \\ rmanzini@unifi.it \\ Leonardo M. Savoia \\ Università di Firenze \\ Isavoia@unifi.it \\ Ludovico Franco \\ Universidade Nova de Lisboa \\ franco.ludovico@gmail.com
}

\begin{abstract}
Ergativity splits between perfect and imperfective/progressive predicates are observed in languages with a specialized ergative case (Punjabi) and without it (Kurdish). Perfect predicates correspond to a VP projection; external arguments are introduced by means of an oblique case, namely an elementary part-whole predicate saying that the event is 'included by', 'located at' the argument. A more complex organization is found with imperfective/progressive predicates, where a head Asp projects a functional layer and introduces the external argument. Our proposal further yields the $1 / 2 \mathrm{P}$ vs. 3P Person split as a result of the intrinsic ability of $1 / 2 \mathrm{P}$ to serve as 'location-of-event'.
\end{abstract}

Keywords: ergative case; oblique case; aspect; person split; Indo-Iranian

\section{Outline}

Ergative alignments in case and agreement observed in Indo-Iranian languages are generally subject to an aspectual split; in Punjabi a person split is also observed. We argue that in Punjabi and Kurdish ${ }^{1}$ the transitivizing

${ }^{1}$ We use primary data, allowing us to base the analysis directly on the intuitions of our native informants. The choice of Punjabi depends on its emblematic case organization (Bailey 1904; Bhatia 1993). Data are transcribed in a broad IPA from the (Doabi) variety spoken in the Indian town of Hoshiarpur; in the transcription we leave out in particular tonal properties (Bhatia 1993). Some variability in the examples reflects the native speakers varying output (for instance as to whether the auxiliary is or is not realized). The Bahdini variety of Kurmanji Kurdish was elicited from Northern Iraqi speakers. The Sorani data are from two informants, one from the town of Mariwan and the other from Sanandaj, both in Iran. 
head introducing the external argument (of transitive and unergative Vs) is better construed as Asp, since it primarily encodes aspect, namely progressive, or more generally imperfective, aspect. For perfects, we propose that no AspP layer is projected; therefore perfects are VPs. This means that a causer/agent cannot be licensed by Asp and can only be introduced via an oblique case, namely the specialized ergative (Punjabi) or an allpurpose oblique (Kurdish). There are two major streams in our discussion, one relating to the aspectual split, and the other relating to the nature of ergative case - which converge in the proposal we put forward. The fact that the two proposals converge in the picture we provide for Indo-Aryan and Iranian languages does not imply that they are logically dependent from one another. In any event, we argue that they both hold in the languages at hand.

As for the aspectual split, there appears to be a fair consensus in recent generative literature that perfect predicates or perfect sentences lack structure present in their imperfective counterparts (Baker \& Atlamaz 2013; Coon 2013; Nash 2014). We present our proposal in section 2. On ergative case, current generative research follows two opposed directions. On the one hand, ergative is treated as an oblique/inherent case (Woolford 1997; Coon 2013). On the other hand early generative attempts at unifying the ergative/absolutive alignment with the nominative/accusative one (the Obligatory Case Parameter of Bobaljik 1993; cf. Massam 2006) are being revived under the umbrella of dependent case (Marantz 1991; Bobaljik 2008; Baker \& Vinokurova 2010; Preminger 2014). As we already mentioned, we take the view that ergative case is an oblique. The morphological evidence favours this conclusion, to the extent that subjects in ergativity splits bear the same case as genitive complements of nouns, dative arguments of verbs, instrumental adjuncts (see section 3.2). Note that although the genitive has sometimes been taken to be a structural case (especially Alexiadou 2001), datives and instrumentals are normally taken to be inherent cases; in the languages we consider, the morphological evidence supports the conclusion that all three are oblique cases (unlike, say, absolutive/nominative). If so, the dependent case algorithm cannot be involved in any general way in ergative alignments, since the algorithm only works by excluding inherent cases (datives, instrumentals, etc.) to begin with. We detail our proposal in section 3 .

Section 4 extends the proposals formulated in sections 2 and 3 to Kurdish, where perfectivity splits are observed either in the absence of a specialized ergative in the case system (Kurmanji) or just in the clitic system (Sorani). We will proceed by constructing syntactic analyses in a 
bottom up fashion, based on the properties of the lexicon of the language and on (mostly) standard minimalist rules and principles. At the end of sections 2-3 we will return to the comparison with other current model and to a brief survey of the overall implications of our proposals for the theory of grammar.

\section{The aspectual split}

In order to understand the Punjabi data, it is useful to have a sketch of Punjabi morphology at hand. There are two nominal classes, conventionally masculine and feminine. A subset of masculine nouns present the inflection $-a$ in the non-oblique singular form (1a) and $-e$ in the oblique singular (followed by postposition) and in the non-oblique plural (1b). The oblique plural masculine (followed by postposition) is in turn realized as -ea (1c). Case postpositions, like ergative -ne, or DOM (Differential Object Marking) -nu attach to the inflectional oblique. The feminine does not display a specialized oblique form. At least some feminine nouns present the inflection $-a$ in the plural as in (2a); another subset of them alternates between a singular with final $-i$ and a plural with $-\tilde{a} \tilde{\imath}$, as in $(2 \mathrm{~b}-\mathrm{c})$. As highlighted by the glosses, the forms without postpositional case suffixes of the type in (1a) or (2a) are traditionally said to be associated with the absolutive case. There is no doubt that morphologically they are just inflected for nominal class (gender) and number. Pending a discussion of the issue in section 2.2, we will simply refer to them as being in the absolute form (Bailey 1904, 8) not in the absolutive case.

(1) a. mund-a 'boy-M.SG.ABS'

b. mund-e 'boy-M.SG.OBL/BOY-M.PL.ABS'

c. mund-ea 'boy-M.PL.oBL'

(2) a. kita:b/kitabb-a 'book.F.SG.ABS/book-F.PL.ABS'

b. kur-i 'girl-F.SG.ABS'

c. kur-ĩã 'girl-F.PL.ABS'

Third person pronouns show a similar case organization to nouns, as indicated in $(3 \mathrm{a}-\mathrm{d})$ for the pronoun $o / e$ 'he/she', where the contrast is remote $(o)$ vs. proximate $(e)$. First/second person pronouns have a specialized form for genitive (4c) besides an absolute and a dative/DOM form (4a-b); they lack ergative. 

(3) a. o/e 3SG.ABS
b. o/e-nu 3SG-DAT/DOM
c. o/e-ne 3SG-ERG
d. o/e-de 3SG-GEN
(4) a. me: 1SG.ABS
b. mi-nnu 1SG-DAT/DOM
c. me-re 1SG-GEN

\subsection{The perfect and its agreement pattern}

In the Punjabi perfect, the verb is a participial form, bearing number and nominal class inflections; this participial form may be embedded under a 'be' auxiliary, which is however optional. In a transitive sentence the internal argument is in the absolute form, the external argument bears the ergative case -ne, and the perfect agrees with the internal argument, as in (5). Inflections directly relevant to the discussion are highlighted in bold, for ease of processing.
(5) a. kur-ĩã-ne
dərvadd $3-\mathbf{a}$
kolt-a
girl-F.PL-ERG door-ABS.M.SG open.PRF-M.SG be.PRS
'The girls opened the door.'
b. o-ne rott-i khadd-i si
s/he-ERG bread-ABS.F.SG eat.PRF-F.SG be.PST
'S/he ate the/some bread.'
c. o-ne kut't-e peddz-e
s/he-ERG dog-ABS.M.PL send.PRF-M.PL
'S/he sent the dogs.'
d. una-ne kitabb-a dekkh-ĩã they-ERG book-ABS.F.PL see.PRF-F.PL
'They saw the books.'

(a)

In an example like (5b), the noun rott $-i$ '(the) bread' consists of the predicative base rott- 'bread' and of the nominal class inflection $-i$ for the feminine. Higginbotham (1985) argues that a nominal base is a predicate with one argument to be saturated (the so-called R-role) and that in English the determiner is the referential material responsible for saturating it, along the lines in (6). 
(6)

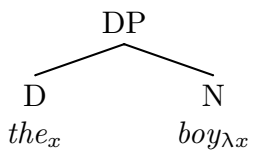

For Punjabi, we propose that the nominal class (gender) morphology overtly visible in this language provides a descriptive content for the Rrole of the predicative base. Closure by an abstract $\mathrm{D}$ operator (Ramchand \& Svenonius 2008) yields a referential reading for the argument. This is illustrated in (7) for rott- $i$ 'bread-NClass', where $\lambda x$ denotes the open place at the predicate 'boy', the $-i$ nominal class morphology provides descriptive content for the $x$ variable and the $\mathrm{D}$ operator binds this descriptive content mapping it to an individual. ${ }^{2}$

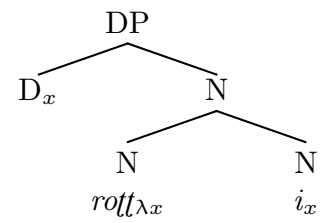

Since it is reasonable to expect that to a similar morphology corresponds a similar syntax and semantics, the perfect participle khadd-i 'eaten' will consist of the $\mathrm{V}$ root, khadd- which has an argument to saturate, namely its internal argument and the $-i$ inflection providing a morphological level saturation for it, as in (8).

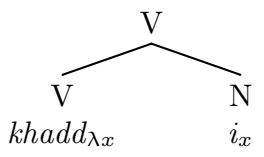

${ }^{2}$ As far as we can tell, Adger \& Ramchand's (2005) feature system is largely compatible with the present proposal. Their $\lambda$ feature translates into a lambda abstractor $\lambda x$ whose variable is introduced by a pronoun with a dependent value $\left(\mathrm{I}_{\mathrm{D}}\right.$ :dep in their notation).

The idea that nominal class is a crucial component of the interpretation of NPs independently surfaces in the literature, especially in discussions of Bantu, e.g., Kihm (2005); Déchaine et al. (2014); Franco et al. (to appear). By contrast, we exclude that the $-i$ inflection could be identified with $\mathrm{D}$. This is because it does not itself bear any definiteness or indefiniteness specifications - i.e., it is compatible not only with an empty definite D of the type postulated in (7) but also with indefinite quantifiers. These behaviours contrast with those of languages with inflections that bear (in)definiteness specifications, also referred to as postposed articles (e.g., Albanian, Manzini \& Savoia 2011a). 
As it turns out, in Punjabi, the inflection of the perfect is sufficient to lexicalize the internal argument of the verb with a pronominal 3rd person reference, as seen in (9). One may of course want to postulate an empty category DP agreeing with the inflection in (9), as in Rizzi (1982). However, accounts of pro-drop have also been proposed where the inflection carries the entire referential burden (Manzini \& Savoia 2007). More generally, taking morphological constituents to carry the burden of argument satisfaction has a considerable tradition in generative studies, starting with the Pronominal Argument Hypothesis of Jelinek (1984). ${ }^{3}$
(9)
a. oval-e
kutt-e-ne
dekkh-ea
that-OBL.M.SG dog-OBL.M.SG-ERG see.PRF-M.SG
'That dog saw him.'
b. oval-e mund-e-ne dekkh-e
that-OBL.M.SG boy-OBL.M.SG-ERG see.PRF-M.PL
'That boy saw them.'

Merger of the substructure in (7) with the substructure in (8) yields the structure in (10) for the perfect predicate (5b). In (10), if we maintain that the $-i$ inflection has pronominal-like content, the relation between rott $i$ and $-i$ is akin to clitic doubling, with $-i$ playing the role of the 'clitic'. In other words, $(r o t t i,-i)$ is a chain, i.e., a single discontinuous argument, where the elementary descriptive content of $-i$ is bound by the referential DP rott $i$, ultimately satisfying the internal theta-role of the verb. This discontinuous element provides the saturation for the internal argument slots of both 'bread' and 'eaten', i.e., 'it $f_{f}$ bread, eaten it $f$ '. Note that the DP and the agreement are local with respect to one another since they are in the same phase (Chomsky 2001) - and furthermore, no other DP intervenes between them, satisfying Minimality (Rizzi 1990; Chomsky 1995).

(10)

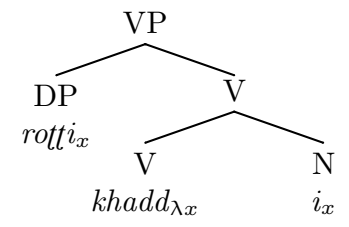

${ }^{3}$ Here however we do not accept the corollary of the Pronominal Argument Hypothesis that lexical DPs doubling the agreement inflections are adjuncts. That does not seem necessary to us - considering for example that in cliting doubling configurations (e.g., in Romance) it is normally assumed that the doubling DP is in A-position. 
In standard minimalist terms, in a structure like (10) the features of rott $i$ and of the $-i$ inflection undergo Agree. The procedure is driven by the presence of uninterpretable phi-features on the verb, acting as probes for the interpretable phi-features of DP. Intuitively, there is a single set of interpreted phi-features corresponding to each argument; copies on predicates are uninterpretable, and agreement is the surface reflex of syntactic processing deleting uninterpretable copies. Technically, a Minimal Search and Match (identity) rule applies to identical, local pairs of phi-features clusters, so that uninterpretable members are eradicated before LF and Full Interpretation can be satisfied.

Here, we grant the premise that each argument slot is associated with a unique set of phi-features; however we take it that nothing prevents us from applying Minimal Search and Match to interpretable pronominal-like pairs of features. The operation can still be driven by Full Interpretation; however what it does is bundling together interpretable phi-feature clusters which correspond to the same argument slot (a sort of chain formation process). ${ }^{4}$ The argument has been made in the literature that Agree proper should be distinguished from other operations which only share a surface outcome with it (say, concord, Giusti 2008), but this is not what we are suggesting here. We maintain that there is a unique Local Search and Match operation in the syntax, which we call agreement, although we are seeking to promote a particular view of it.

The analysis of transitive sentences in (10) makes predictions on intransitive sentences. Consider first Vs which on cross-linguistic grounds we may take to be unaccusative, i.e., to take only an internal argument (a theme). The argument appears in the absolute form and agrees with the verb, as shown in (11). By contrast, with unergative Vs, the sole argument of the predicate is the external argument introduced by ergative case and the perfect turns up in an invariable, non-agreeing form, as in (12).

\footnotetext{
${ }^{4}$ The same is true for Adger \& Ramchand (2005, footnote 14), on whose framework see footnote 2 .
} 

(12) a. mund-ea-ne dor-ea /boll-ea si boy-M.PL.OBL-ERG run.PRF-M.SG talk.PRF-M.SG be.PST 'the boys ran/talked'
b. kur-i-ne /mund-e-ne hass-ea si girl-F.SG-ERG boy-OBL.M.SG-ERG laugh.PRF-M.SG be.PST 'the girl/the boy laughed'

The pattern of unaccusative Vs in (11) is expected on the basis of the structure in (13). The verb inflection provides an (inflectional-level) lexicalization of the internal argument within the $\mathrm{V}$ constituent. This clitic doubles/agrees with the internal argument DP, which merges with V to yield a VP structure.

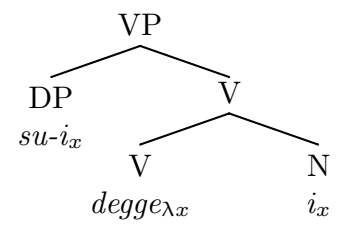

The pattern of unergative Vs in (12) on the other hand includes an invariable masculine singular inflection. Since the perfect participle inflection lexicalizes the internal argument - or probes for it in canonical minimalist terms - we expect to find that it does not agree with the sole argument present in (12), which is an external argument. However, this does not automatically explain the invariable masculine singular inflection. In standard minimalist terms, one may say that in the absence of suitable goals the probe is checked by default - and realized as the morphophonological Elsewhere. In present terms, one could say that in the absence of an internal argument, the obligatory agreement inflection slot is filled by what in the pronominal system would be known as an expletive form. An alternative is suggested by the conception of unergative $\mathrm{Vs}$ as concealed transitives initiated by Hale \& Keyser's (1993). In this tradition, unergatives involve a two-tiered structure, consisting of a nominal(-like) root and of a light verb. One way to maintain the idea that all agreement inflections have an interpretable content (or are checked by an interpretable content) is to say that in (12) the invariable inflection matches the incorporated object of unergatives. ${ }^{5}$

${ }^{5}$ Preminger (2014) recently stressed the importance of default inflections for the theory of agreement. He argues that standard minimalist (un)interpretability should be abandoned in favour of mere valuation of features. Lack of valuation by a goal does 
Summarizing, we can construct the perfective VP in (10) bottom up from its elementary lexical components, interacting simply with morphosyntactic Merge (responsible for the creation of constituent structure) and with Full Interpretation (ultimately responsible for agreement). No abstract functional heads are necessary so far. Interpretively, the VP conveys a state, hence a property, resulting from an event, hence a past tense. Progressive verbs, like perfect verbs, are participial forms. However, they present a more complex internal (morphological) organization which projects a more complex syntax, as we will see in the next section, and a process interpretation.

\subsection{The imperfective/progressive and the two-layer structure of predicates}

With the imperfective/progressive participle, both the internal and the external argument can surface in the absolute form as in (14), at least when the internal argument is non-human or indefinite; the participle agrees in gender and number with the external argument of transitives. When combined with a past auxiliary, the participle yields a past progressive interpretation, as in (14c).

(14) a. o mund-a dekh-d-a/-i (a)

s/he.ABS boy-ABS.M.SG see-PROG-M.SG/-F.SG be.PRS

'S/he is seeing a boy.'

b. mund-a/ mund-e dərvaddz-a khol-d-a/-e

boy-ABS.M.SG BOY-ABS.M.PL door-ABS.M.SG open-PROG-M.SG/-M.PL

'The boy/the boys is/are opening the/a door.'

c. o kutt-a dekh-d-a/-i si

s/he.ABS dog-ABS.M.SG see-prog-M.SG/-F.SG be.PST

'S/he was seeing a/the dog.'

Among intransitive Vs, unergatives reproduce the transitive pattern in that, their only argument, which is the external argument, agrees with the verb and surfaces in the absolute form, as in (15).

(15) a. mund-a/ mund-e hassə-d-a/-e si

boy-ABS.M.SG boy-ABS.M.PL laugh-PROG-M.SG/-M.PL be.PST

'The boy/the boys was/were laughing.'

not lead to the crashing of the derivation but to automatic assignment of default values to the probe. See section 3.3 for further discussion. 
b. kur-i/ kur-ĩã $\quad \operatorname{ron}-\mathrm{d}-\mathbf{i} / \tilde{\mathbf{1}} \tilde{\mathbf{a}} \quad$ (a)

girl-ABS.F.SG girl-ABS.F.PL cry-PROG-F.SG/-F.PL be.PRS

'A/the girl/the girls cries/cry.'

c. me:/ appa bol-d-i/-e a

I.ABS(F) we.ABS talk-PROG-F.SG/-M.PL be.PRS

'I/we am/are talking.'

However, unaccusative Vs also behave like unergatives. Thus the internal and sole argument of the verb in the absolute form agrees with the verb, as in (16).

(16) a. mund-a/ mund-e deg-d-a/-e boy.ABS.M.SG boy.ABS.M.PL fall-PROG-M.SG/-M.PL

'A/the boy/ the boys is/ are falling.'

b. me: aung-i/-a

I.ABS come.PROG-F.SG/-M.SG

'I(m/f) am coming.'

Let us consider the examples in (14). In the discussion of the perfect, we only introduced the VP layer of structure involving the verb and its internal argument; we delay the issue how the external argument is introduced in the perfect (namely by ergative case), until we consider oblique cases in section 3. The question is how the external argument is introduced in the progressive. The standard minimalist model, developed for English, assumes a two-layered verbal structure where the internal argument is introduced by the $\mathrm{V}$ predicate, while the external argument is introduced by the transitivizing predicate $v$.

In Punjabi, we note that the progressive participle has a complex internal structure, as detailed in (17) for dekh-d-a 'see-PROGR-MSG'. Specifically, the lexical base combines with the aspectual (Asp) inflection - $d$ - for the progressive, specifying an unachieved state-of-affairs associated with transitory participants. The phi-features inflection picks up the external argument of transitives and the sole argument of intransitives.

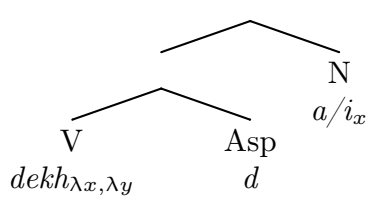


The presence of Asp (i.e., progressive) morphology requires the projection of a two-tiered syntactic structure [AspP [VP]], yielding the tree in (18) for sentence (14a). In (18), the lower VP tier is similar to that postulated for perfects, with munda 'a boy' satisfying the internal argument slot of the predicate. However, the extra Asp structure allows a further argument to be introduced as Spec of AspP, namely o 'he' in (18). This is interpreted as the external argument, i.e., as the argument (causer or other) applied to the elementary VP event, defined by the predicate and its internal argument. In this respect the proposed AspP in Punjabi verbal forms includes the syntactic properties generally associated to the Chomskyan vP. The structure in (18) is compatible both with syntactic movement of the verbal head dekhda, as assumed in Chomsky (1995), and with PF movement, as suggested by Chomsky (2001). We take the latter to mean that the syntactic tree has a single position of merger for the verbal head, and externalization procedures indicate in which of its functional projection it is hosted in a particular language (and sentence type).

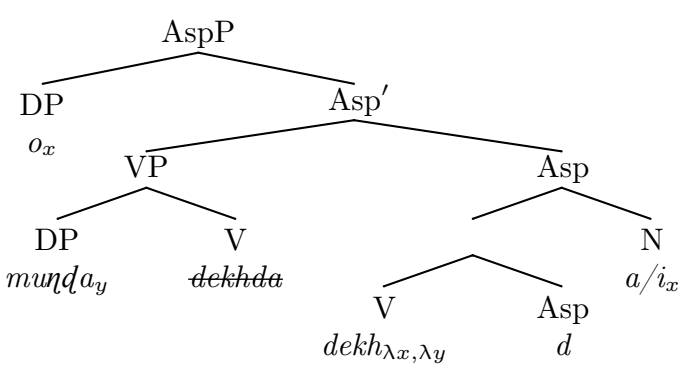

Consider then agreement. In (18), two DPs are present in the same phase as the phi-feature inflection - $a$, namely the internal argument and the external argument DP (on imperfective/progressive aspect being embedded into the first phase, cf. Harwood 2015). Since the phi-features inflection - $a$ attaches not to $\mathrm{V}$, but to the $\mathrm{V}$-Asp complex, we take the external argument to be closest to $-a$, in that they are merged under the same Asp projection. Hence the phi-feature inflection - $a$ agrees with the external argument - or in present terms it concurs to the satisfaction of the same argument slot.

As before, on the basis of a pronominal(-like) construal of agreement morphology we expect that the latter is sufficient to carry reference to the 3rd person - which is correct, as illustrated in (19).
(19) a. kita:b
$\operatorname{par}-\mathbf{d}-\mathbf{a} / \mathbf{i}$
a
book.ABS.F.SG read-PROGR-M.SG/F.SG be.PRS
' $\mathrm{S} /$ he is reading the book.' 

b. son-d-a/i
$\mathrm{a} / \mathrm{si}$
sleep-PROG-M.SG/F.SG be.PRS/PST
'S/he is/was sleeping.'

The Asp layer of structure introduced by $-d$ - morphology is always present in progressives, including in the progressive of unaccusatives, where the single argument is discharged within the VP, and the Asp layer does not introduce any argument, as in (20). In (20), the phi-feature inflection - $a$ agrees with the closest argument in the structure, i.e., the internal argument - or in present terms it concurs to the satisfaction of the internal argument slot.

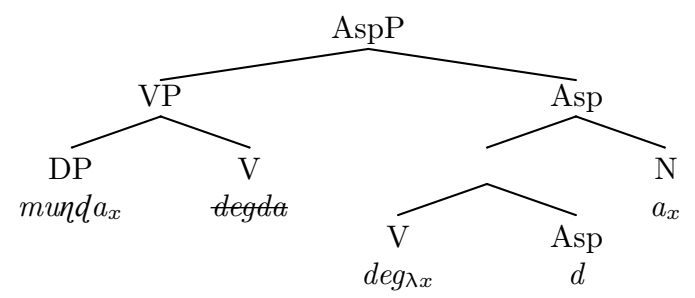

Note that if our discussion is correct, agreement in the perfect and in the progressive is governed not just by two different heads (V and Asp) but also by two slightly different sets of conditions. Agreement in the perfect depends on the notion of internal argument, while in the progressive it is sensitive to the notion of closest argument - starting with its own projection, hence its Spec (i.e., the external argument), and eventually picking the internal argument in the VP projection if there is no external argument. Similarly, in section 3, we will see that the distribution of ergative case in the perfect is sensitive to the notion of external argument.

A TP layer is also present in Punjabi - and realized by the 'be' auxiliary, as for instance in (21) (embedding (18)). However, there is no evidence that the auxiliary, which is itself uninflected for phi-features, is connected to agreement. The same auxiliary is also observed in the perfect, so that its presence or absence cannot be the source of the perfect/progressive asymmetry. 
$(21)$

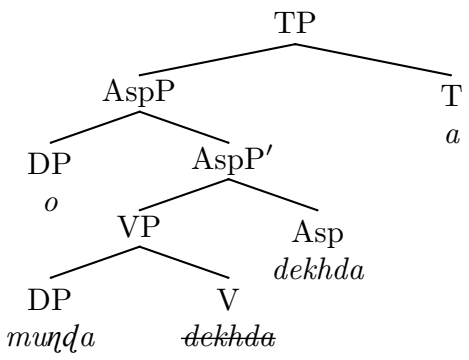

As we saw at the outset, morphologically the absolute forms in (21) only display nominal class and number properties and no case. However, within standard minimalism one would still say that absolute forms like those in (21) are associated with abstract absolutive case ${ }^{6}$ because of Vergnaud's (2008) Case Filter, encoded in minimalist terms by the uninterpretable case feature. The intuition is that chains (i.e., n-tuples of referential material ultimately satisfying an argument slot) must be "visible" and that case satisfies visibility. According to Chomsky (2001), furthermore case checking is parasitic on agreement. However, in (18) we have a single agreement inflection and two different DPs, each needing case via agreement under this version of the theory. Indeed various models have sprung up where each probe can check more than one goal, namely Multiple Agree (Nevins 2011), Cyclic Agree (Béjar \& Rezac 2009). However, our assumption that agreement morphology is an elementary pronoun of sorts excludes this type of approach. The fact that all phi-features are interpretable means that they cannot be overwritten and in general they cannot conflate two different referents, even when realized on predicates. We are nevertheless left with the problem whether the absolute forms have case and how they have it licenced.

A different approach to case is advocated by Marantz (1991). First, he argues that "Nominal arguments are licenced by (extended) projection, not by Case". This triggers a number of issues, for which there are however convincing (and even standard) alternatives. In particular, A-movement is determined not by lack of case but by the EPP; the distribution of PRO cannot be governed by case, since the control (PRO) interpretation is easily found with finite complements (e.g., of Balkan languages). For Marantz, case is therefore a morphology-internal phenomenon. The second part of his approach is a morphology-internal algorithm to determine the distribution of cases, characterized by existence of a so-called dependent case, i.e., the case assigned when two DPs in the same sentence find themselves without

\footnotetext{
${ }^{6}$ Eventually this is realized as a morphological default (Legate 2008).
} 
an inherent case. Recently, this approach has been adopted by Bobaljik (2008) - while a number of theorists have adopted dependent case, but as a syntactic algorithm (Baker \& Vinokurova 2010; Preminger 2014).

For present purposes, we have two options open. The first one is to adopt the dependent case algorithm in the syntax, saving the idea that all lexical DPs (or all lexical chains) have a case; it is true that we will argue against ergative as a dependent case, but this is logically independent from its adoption for nominative-accusative alignments. The second alternative is more consonant to the present outlook, namely that (following Marantz's original idea) the two DPs in (21) do not in fact have any case and are simply attached to the verbal projections of the predicate satisfying its argument slots because of their nominal class, number and (in)definiteness properties. In section 3 we propose that oblique cases are elementary predicates (for instance the part/whole predicate for genitives/datives) to which the arguments they inflect are attached. At least in languages like Punjabi which do not have any direct case morphology, we would therefore like to say that attachment to $\mathrm{V}$ and $\mathrm{v} /$ Asp does not involve case at all. Yet many questions remain open (including the nature of morphological nominative and accusative case in languages that have them) - so that the entire issue must be left for further research.

\subsection{Discussion: competing accounts of the aspectual split}

Summarizing so far, we have suggested a formalization of the ergativity split under which perfects reflect a more elementary organization of the predicate than progressives/imperfectives. We surmise that the perfect participle in languages like Punjabi is a VP predicate, essentially displaying the same internal complexity as an NP or AP predicate. Only a bare VP predicate is needed in order for the perfect reading to be obtained. By contrast, the progressive participle has a more complex internal configuration including an Asp head introducing the external argument, whereas in the perfect the external argument is introduced by the ergative -ne 'case' (on which more in section 3). In the progressive, transitivity is built into the structure by Asp - which means that both subject and object can be introduced as non-oblique DPs.

The idea that ergative alignments correspond to a somewhat more elementary organization of the predicate, or the sentence, than nominative alignments has been consistently explored in recent generative work. For Baker \& Atlamaz (2013), the perfect is passive-like and differs from the imperfective in that it involves a non-phasal v; their proposal will be 
addressed in more detail - and rejected - in connection with Kurdish in section 4. Laka (2006) proposes that nominative alignment implies a biclausal structure in Basque. Coon (2013) has a similar analysis of Chol (Mayan). In Coon's analysis, both perfectives and imperfectives have the same underlying predicate structure - essentially the kind structure that we have attributed here to perfects. Imperfectives however are embedded under an aspectual auxiliary, determining the switch in alignment. Coon (2013, 200) acknowledges that in a language like Hindi "there is not always such a clear structural difference between perfective and imperfective forms: perfective forms may also appear with a final auxiliary. [...] Nevertheless, while the auxiliary may be dropped in the perfective, it is obligatory in the imperfective (Anoop Mahajan 2011, personal communication)". As it turns out, our Punjabi speakers displayed no asymmetry between perfects and progressives; the present auxiliary is often dropped, though it can also be realized. We have nothing to say on the matter of Chol (or of Basque) - but applying the same abstract template to Indo-Aryan seems to conflict with the evidence. This is not to say that Chol and Indo-Aryan do not share the same basic property of added Aspectual structure in the imperfective. However, it is part of the present outlook that underlying universals in the conceptual components do not necessarily translate into universal syntactic templates.

An analysis of the aspectual split closer to ours is recently proposed by Nash (2014). Nash concludes in favour of "the absence of any Aspect category" in the Georgian aorist, where "the event is just named without referring to the specifics of its internal temporal organisation as if it were 'nominalised' in some sorts". By contrast, imperfective aspect is introduced by a specialized aspectual node (Event), which is also responsible for licencing the external argument, much like Voice in the sense of Harley (2013). Importantly, here the contrast between the various aspectual alignments is ascribed directly to the overt morphological constituency of the participles involved, as they project to the syntax. In other words, we have adopted a categorial organization which reflects the overt morphological structuring of the language, so that the external argument is introduced by progressive Aspect, not by some $v$ or Voice category dedicated as an external argument introducer. ${ }^{7}$

${ }^{7}$ A general issue arises when the present approach is compared to cartographic literature concerning the distribution of TMA categories. Cinque $(1999,57)$ proposes the order Tense $>$ Aspect $_{\text {perfect }}>$ Aspect $_{\text {progressive }}>$ Voice $>$ V based, among others, on the evidence of English I have been running, where the progressive -ing form is embedded under the perfect been (cf. more recently Ramchand \& Svenonius 2014; 


\section{The ergative and other oblique cases}

We take ergative to be an oblique case - of which it displays the morphological makeup in Punjabi. We have seen in (1), repeated as (22a-c) for ease of reference, that a subset of masculine nouns present the inflection - $a$ in the absolute form singular (22a), while - $e$ inflects the absolute form plural, but also the oblique (non-absolute) singular, as in (22b); the oblique plural is -ea as in (22c). The -ne ergative suffix attaches not to the absolute stem, but to the oblique-inflected stem, exactly like the - $n u$ suffix (dative, DOM) and the -de suffix (genitive) - as exemplified in (22d-f).

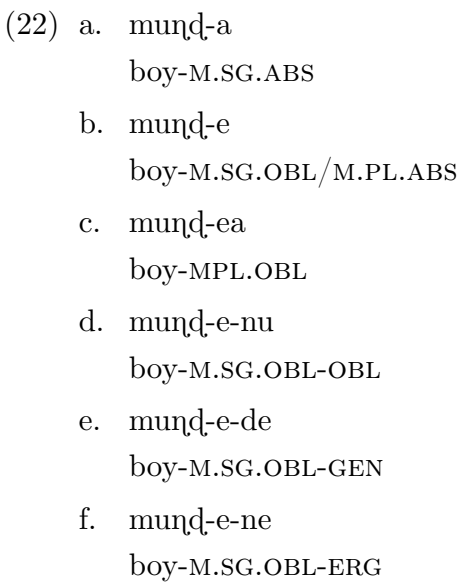

The nature of ergative case depends among other things on the larger issue of how to treat oblique cases. Oblique cases can be reduced to Chomsky's

Harwood 2015). The question is whether and how the fact that perfects are structurally smaller than progressives is compatible with the ordering of perfect above progressive in Cinque's hierarchy. The obvious conclusion to draw from the facts is that the $\mathrm{Asp}_{\text {perfect }}$ of Cinque and the perfect participle instantiate two different "aspects" which are independently ordered with respect to one another. The Asp perfect of Cinque is in the last analysis a temporal notion, concerning an event presented as bounded; in the terms of Smith (1991), the event is contained within the reference time of the sentence. The perfect participle denotes a property, not unlike a nominal or adjectival predicate - implying that the event from which the property or state results is concluded and in fact past.

Another possible view of the matter is provided by Nash (2014), who argues that the Georgian aorist, characterized by ergative alignment, is an instance of neutral aspect, defined by Smith (1991) as a partially bounded aspect (beginning of the event within the reference time, but event potentially continuing beyond). Nash further suggests that the lack of aspectual structure characterizes neutral aspect. 
(2001) agreement model of case, if we assume that there are abstract heads, such as Appl heads (Pylkkänen 2008), endowed with uninterpretable features and that oblique cases are a byproduct of Agree with these heads. However, the morphosyntactic reality is that cases are uniquely represented in the morphology of nouns (and nominal constituents) and not on the verb or verbal constituents. Therefore we follow a different tradition of studies, represented in formal approaches originally by Fillmore (1968), in which oblique cases are inflectional counterparts of Ps, i.e., elementary predicates. $^{8}$

Morphologically, the paradigm in (22) leaves little doubt that absolute forms, endowed with a specialized stem inflection, and not followed by any case postposition, are set apart from other forms, bearing a different stem inflection and followed by the case postposition. In this section, we show that this morphological contrast corresponds to a syntactically motivated difference between non-oblique forms attached directly on the verbal spine (see the discussion in section 2.2) and oblique forms, which require the extra predicative content provided by so-called case. Therefore it should be emphasized that oblique case is a syntactic construct for us - though syntax maps transparently to morphology in this instance (which we take to be a welcome result).

Specifically, we take the basic oblique case of natural languages to correspond to the part-whole elementary predicate, notated $(\subseteq)$, in the terms of the model of case we have discussed in our recent work (Manzini \& Savoia 2011a; Franco et al. 2015); so a 'possessor' (genitive, dative) is essentially a 'whole' including a 'part' (the possessee). Evidently this implies that we reject treatments of genitive as a structural case (e.g., Alexiadou 2001). Importantly for present purposes, an important stream of literature connects 'ergative' structures with 'possession' structures. Montaut (2004, 39) quotes Benveniste's (1966, 176-186) conclusion that "the Old Persian structure [...] is intrinsically possessive in its meaning, and is analogical with the periphrastic perfects in Latin (mihi id factum, me-DAT this done)". ${ }^{9}$ In other words, the external argument is treated not so much as a causer/agent in an event as the possessor of a property.

${ }^{8}$ At a deeper level, the main fact about case that the minimalist program strives to express is that case cannot be an intrinsic property of nominal heads or phrases, in the same way as number or person are. Chomsky (2001) resolves this dilemma by proposing that case is an epiphenomenon of phi-features. We address the same problem, by denying that case (or at least oblique case) is a nominal feature at all.

${ }^{9}$ Benveniste's view is criticized by Iranologists (e.g., Cardona 1970), who revive the more traditional characterization of the past participle construction of (Old) Iranian 
The line of inquiry relating ergativity to nominal structures, is not just relevant for Indo-European languages. In the words of Johns $(1992,68)$, "similarities in case and agreement between transitive clauses and possessive phrases is a long-standing issue in Eskimo linguistics. [...] The first of these similarities is that the case assigned to the specifier (possessor) of a possessed noun is the relative case, the same case that is assigned to the actor in the transitive construction". Thus, for Johns, a transitive declarative sentence "is constructed syntactically along the lines of "The bear is the man's stabbed one'. Semantically of course it must have the meaning 'The man stabbed the bear'" (op.cit., 61). In our terms, as we will see, ergative case (as in Punjabi) or the all-purpose oblique case of Kurdish on the external argument DP correspond to an oblique 'possessor' relation between DP and the VP predicate (a property).

\subsection{Dative and genitive}

The - nu suffix of Punjabi can be identified with the dative in that it lexicalizes the second internal argument of ditransitives, i.e., the goal. As we may expect for an oblique complement, this is independent of perfect (ergative) vs. progressive (nominative) alignment, as shown in $(23 \mathrm{a}-\mathrm{c})$ and (23d) respectively.

(23) a. me: ti-nnu kita:b din-d-i (a)

I.ABS(F) you-OBL book.ABS.F.SG give.PROG.F.SG be.PRS

'I give you the book.'

b. tu: kəmidzə o-nu peddz-d-a/-i a

you.ABS(M/F) shirt.ABS-F.SG he-OBL send-prog-M.SG/-F.SG be.PRS

'You are sending the shirt to him.'

c. o mi-nnu/una-nu kita:b din-d-i/-a a

s/he.ABS me-OBL/they-OBL book.ABS.F.SG give-PROG-F.SG/-M.SG be.PRS

'S/he is giving the book to him/me/them.'
d. o-ne kita:b
ditt-i
(si) una-nu
s/he-ERG book.ABS.F.SG give.PRF-F.SG be.PST they-OBL
'S/he gave the book to them.'

Dative, as the second internal argument of ditransitives in examples of the type in (23), has been connected to possession in the formal literature, at

as a "passive construction". Nevertheless Lazard (2005); Butt (2006); Haig (2008), among others, come out in favor of the possessive analysis. 
least since Kayne (1984). In other words, 'I give John a book' is roughly 'I give [John HAS a book]' (cf. Pesetsky 1995; Beck \& Johnson 2004; Harley 2002). Following Belvin and den Dikken (1997), we construe possessors as 'zonally including' the possessee. Following Manzini and Savoia (2011a; 2014a), Franco et al. (2015), we notate the 'inclusion' (or part-whole) relation as $(\subseteq) \cdot{ }^{10}$ In terms of the $(\subseteq)$ characterization of datives, the structure of a sentence like (23a) will take the form in (24). The - $n u$ dative postposition introduces a possessor/inclusion relation which takes as its internal argument the DP to which it attaches, 'you' in (24), and as its external argument a DP in its immediate domain, 'book' in (24). What the dative case, or more properly the dative elementary predicate says is that 'the book' is in the inclusion zone (possession) of the hearer 'you'.

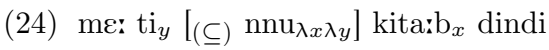

As one may expect on the basis of the analysis in (24), Punjabi -nu provides not only the lexicalization of dative possessors in ditransitive sentences, but also in sentences with a nominal predicate like (25), where possession includes that of physical or mental states. For instance, 'I have a fever' is literally rendered as 'to me is a temperature'.

(25) a. mund-e-nu/ kur-i-nu/ mi-nnu/ ti-nnu bukhar/pokh/dhar a boy.M.SG.OBL-OBL girl-F.SG.OBL I-OBL you-OBL fever/hunger/fear be.PRS 'The boy/the girl/I/you is/are feverish/hungry/afraid.'

b. oval-i kita:b mi-nnu pəsand a-i

that-F.SG book-ABS.F.SG me-OBL like come.PRF-F.SG

'I came to like that book.'

In short, we impute an interpretive content to the descriptive 'dative case', namely $(\subseteq)$. This content is predicative, and it can be realized by prepositions (English 'to'), by verbs (English 'have') and by nominal inflections (Punjabi -nu). The $(\subseteq)$ content is also primitive - but it is not a 'case'; it is an elementary predicate. The inflectional realization of the $(\subseteq)$ predicate (connecting the argument to which it attaches to the main predicative core of the expression) is conventionally called a case. But in present terms, case is definable at most as the crossing of the more elementary notions of atomic predicate and inflectional realization. This is a fairly traditional stance - which however denies that there is anywhere a primitive property

10 The same authors propose that since relational content in DPs is generally carried by the category $\mathrm{Q}$, one should identify the oblique case as $\mathrm{Q}(\subseteq)$. 
case inscribed in the phi-feature bundles of a $\mathrm{D}(\mathrm{P})$. In this sense, it complies with the minimalist reduction of case to more primitive properties (cf. fn. 8). ${ }^{11}$

Moving on from dative, the genitive in Punjabi yields a person split of sorts, since it is realized as $d$ - on lexical nouns, but as $r$-on Participant pronouns, as in (26). In either instance, the genitive element bears an inflection agreeing with the head noun. ${ }^{12}$
a. mund-e-d-i/-ĩã kita:b/ kitabb-a
boy-OBL.M.SG-GEN-F.SG/-F.PL book.ABS.F.SG book-ABS.F.PL
'the book/the books of the boy'
b. te-r-i/-ĩã kəmidd3/ kəmiddz-a
you-GEN-F.SG/-F.PL shirt.ABS.F.SG shirt-ABS.F.PL
'your shirt(s)'

The genitive canonically corresponds to possession, as in (26), and is therefore a candidate for $(\subseteq)$ status in present terms. Therefore we propose the partial structure in (27) for (26a), where the -de genitive morphology introduce a $(\subseteq)$ or possession relation between the argument to which it attaches 'the book' (the part or possessum) and the head DP 'the boy' (the whole or possessor). ${ }^{13}$ Therefore the same content $(\subseteq)$ is lexicalized in Punjabi

11 Although we have assumed that the fundamental oblique of Punjabi, responsible in particular for datives, is the 'part/whole' (or 'inclusion') relation, possession is often identified with a location, cf. Freeze (1992); Lyons (1967). Butt (2006), writing on Indo-Aryan cases, takes the locative (spatial) dimension to be primitive in their definition. Manzini and Savoia (2011a; 2011b) argue in favour of the primitive nature of the part-whole relation on the basis of considerations regarding the morphological shape of Indo-European and other languages. Thus inflections alone suffice for the lexicalization of the more elementary possession/part-whole relation in languages where even the simplest of locative relations require the lexicalization of Ps. Specifically, in discussing the syncretic lexicalizations of dative and locative in Albanian, Manzini and Savoia construe locative as a specialization of the part-whole relation, roughly ' $x$ included by $y, y$ a location', where different locatives introduce different locative restrictions on inclusion. This is compatible with the expression of (certain types of) possession as locations, for instance alienable possession in Palestinian Arabic according to Boneh \& Sichel (2010).

12 The inflection of the genitive DP agreeing with the head noun appears to be fundamentally the same as the ezafe of Iranian languages (cf. section 4 on Kurdish). The latter precedes the genitive, but it also forms a constituent with it and agrees with the head noun (Philip 2012; Franco et al. 2015).

${ }^{13}$ Apart from dative - $n u$, genitive - de/re and ergative - ne, other postpositions of Punjabi do not attach directly to the absolute or oblique form of the (pro)noun, but 
either by the dative $-n u$ or by the genitive $-d e /-r e$. We propose that the two different lexicalizations correspond to a contextual sensitivity of the category $(\subseteq)$ in Punjabi. Thus $(\subseteq)$ is lexicalized as $-n u$ when attached to sentential projections, while it is lexicalized as -de/-re when it is attached to nominal categories. Note that cross-linguistically, dative/genitive syncretisms are widespread, specifically in Indo-European languages (modern Greek, Albanian, Romanian, class I of Latin, Kurdish as reported in section 4 below), strengthening the conclusion that the genitive and the dative form a natural class.

(27) $\left[\text { munde }_{y}\left[_{(\subseteq)} \mathrm{d}_{\lambda x \lambda y}\right]\right]_{x}$ kita: $_{x}$

Before concluding on obliques other than the ergative, we must mention that - $n u$ shows up not only as the lexicalization of dative (possessor, experiencer, etc.) but also as the DOM case in the sense of Plank (1984); Aissen (2003), as illustrated in (28) for the progressive and in (29) for the perfect. The DOM alignment in (28)-(29) becomes necessary if the internal argument of transitives is human and definite (or at least one of the two), including pronouns; if so, it shows up with the -nu postposition/case. The agreement pattern of the progressive (with the external argument of transitives) is not disrupted. In the perfect, the DOM case on the internal argument implies lack of agreement between it and the participle. Since the participle does not agree with the ergative external argument either, it surfaces in an invariable masculine singular form.

(28) a. val-i

t fabb-i dərvaddz-e-nu khol-d-i

a

that-ABS.F.SG key-ABS.F.SG door-OBL.M.SG-OBL open-PROG-F.SG be.PRS

'That key opens the door.'

b. me: mund-e-nu/bill-i-nu/ti-nnu dekh-d-i a

I.ABS(F) boy-OBL.M.SG-OBL/cat-F.SG-OBL/you-OBL see-PROG-FSG be.PRS

'I am seeing the boy/the cat/you.'

rather to the (pro)noun followed by the genitive morphology, which surfaces in the invariable form -de/-re, as in (i)-(ii) (cf. also Bailey 1904).
(i) me-re-to
me-GEN-from
(ii)
o-de-nal

This is consistent with Svenonius (2006), who brings out the existence in the internal structure of PPs of both case components (here the genitive -de/-re) and of components with lexical/interpretive affinity to nouns, namely Axial Parts (here the embedding Preposition). 
c. me:/tu: o-nu dekh-d-a/i

I.ABS/you.ABS him-OBL see-PROG-M.SG/F.SG

'I/you(m./f.) am/are seeing him.'

(29) a. mund-e-ne rott-i-nu khadd-a ni

boy-OBL.M.SG-ERG bread-F.SG-OBL eat.PRF-M.SG NEG

'The boy did not eat the bread.'

b. o-ne mi-nnu/ti-nnu dekkh-ea

s/he-ERG me-OBL/you-OBL see.PRF-M.SG

'S/he saw me/you.'

c. kutt-e-ne mi-nnu dekkh-ea

dog-OBL.M.SG-ERG I-OBL see.PRF-M.SG

'The dog saw me.'

The DOM case is traditionally taken to be an accusative and glossed as such. However, at least morphologically the DOM case of Punjabi is not an accusative. Indeed it attaches to the same oblique stem as all other oblique postpositions in Punjabi - besides coinciding with the (goal, experiencer etc.) dative. One may think this latter fact to be a mere matter of morphophonological coincidence-except that across the Indo-European languages the expression of DOM (where present) systematically coincides with that of the dative. This is true in the Romance languages, where dative and animate/specific objects are generally introduced by the preposition $a$ 'to', ${ }^{14}$ in Hindi, where the relevant postposition is -ko (e.g., Mohanan 1994) or in many Iranian varieties, where DOM and dative are both expressed by the postposition -ra/-re (e.g., Mazandarani, Lecoq 1989). A further obvious argument in favour of the oblique status of DOM is the fact that it is incompatible with agreement in the perfect, e.g., in (29).

Manzini and Savoia (2014b), Manzini and Franco (to appear) therefore take the dative/DOM syncretism at face value and propose that dative covers both goal and DOM contexts. In the latter dative, i.e., $(\subseteq)$, introduces a relation between the human/specific internal argument and the $\mathrm{V}(\mathrm{P})$ elementary event. This corresponds to the structure in (30) for a

14 ' $a$-NP' constructions show up in Ibero-Romance, in Engadinese, in Corsican, in Central and Southern Italian, in Sardinian. Manzini and Savoia (2005) note that in Italian varieties where the dative is lexicalized by a preposition other than $a$, DOM is introduced by the same preposition (e.g., ma 'to', $d a$ 'to, from'). Nevertheless Romanian, which has inflectional datives, introduces DOM by means of the locative preposition $p e$ 'on, through' (on locatives, cf. fn. 11). In short, the dative/DOM syncretism is a general Romance characteristic - without being a necessary one. 
sentence like (28b), where the human and definite DP munde 'the boy' is attached to the core of the sentence by the $(\subseteq)$ elementary predicate, lexicalized by $-n u$. Interpretively, the argument that $-n u$ attaches to has in its domain of inclusion not another DP but the $\mathrm{V}$ event dekh(da) 'see(ing)'. To be more precise, if we make reference to the decomposition of predicates into a light verb and a stative (nominal) component (i.e., 'see' as 'have sight (of)', 'help' as 'give help (to)', 'call' as 'make a call (to)' etc.) the internal argument is introduced as a possessor of the embedded elementary predicate (rather than a theme of the complex predicate). ${ }^{15}$

(30) me: munde $\left.{ }_{(\subseteq \subseteq)} \operatorname{nu}_{\lambda x, \lambda y}\right]$ dekhdi $x$

Informally, what the DOM phenomenon amounts to (in Punjabi and crosslinguistically) is the requirement that human/definite DPs cannot be introduced within VP as themes. However, the gist of DOM is not so much to insure that specific/human arguments do not have a theme attachment (in the negative) - rather it is to insure that specific/human arguments have an attachment as high (or higher) in the sentence as any other argument, hence either as agents/causers/experiencers or as possessors. We provide a schematic representation of this generalization in (31). The proposal in (31) as to the oblique nature of the DOM makes the prediction that DOM structures will behave as if they involved an unergative $\mathrm{V}$ with respect to agreement in the perfect. Specifically, the absence of an internal argument triggers the presence of the invariable inflection.

\section{(31) DOM (Punjabi)}

EA $\left[{ }^{*}(\subseteq)\right.$ definite/human $]$ V]

In (31) we stipulate among other things that the oblique embedding of definite/human DPs only holds in structures with an external argument. This is because the theme of unaccusative Vs, despite being an internal argument, is also the highest argument in its structure and is excluded from undergoing DOM. Manzini and Franco (to appear) state essentially the same constraint without reference to EA. However, they work with nominative alignments in Western European (Romance) languages where the internal argument of an unaccusative is guaranteed to raise out of the VP to the EPP position. As we briefly mentioned in section 2.2, Punjabi does have a TP projection and nothing stands in the way of assuming

${ }^{15}$ Manzini and Franco (to appear), taking the usual approach in minimalist models, associate the light verb component of transitive and unergative verbs with a syntactic $v$ projection. 
that raising to the EPP position takes place in the ergative alignment as well, extracting the closest argument (external argument or internal arguments of transitives). If so, in (31) we do not in fact need to mention EA - although we preferred to keep to conservative assumptions in stating the generalization.

\subsection{The ergative}

Let us consider next ergative -ne. Though we assume that it is an oblique case, the point of the discussion to follow is that it is not a case connected to the expression of the external argument, as argued by an important stream of literature from Woolford (1997) to Coon (2013). We return to literature treating it as a dependent case in section 3.3.

The hypothesis that the ergative element is a counterpart of the $v /$ Voice functional head, responsible for introducing the external argument is quite natural. However, both external and internal reasons militate against it. The historical literature debates the etymology of -ne ("obscure" for Montaut 2004), connecting it most often to the Sanskrit instrumental. However, Butt (2006), Butt and Ahmed (2011), Verbeke and de Cuypere (2009) argue that a much better origin is to be sought in the -ne dative still preserved in some Indo-Aryan languages, for instance Haryani as in (32). The -ne postposition is seen to lexicalize the external argument of the perfect (the ergative) in (32a), the goal dative in (32b) and the DOM case in (32c). The co-occurrence of an ergative subject with a DOM object in the perfect yields a double -ne pattern in (32c). Indeed Butt and Ahmed mention the similarity of Punjabi -nu and -ne as suggestive of a common etymology. If we maintain that dative/DOM instantiates $(\subseteq)$, we are led to conclude that in a language like Haryani in (32), ergative is nothing else than a 'possessor' (of the event), recalling the proposal made for Iranian languages by Benveniste (1966), Montaut (2004), among others.

(32) a. sad:h nae bud:hiaa ki jhu pr:ii kii kun mae laat maaryi

Sadhu ERG old.lady GEN cottage GEN corner in leg hit

'The Sadhu kicked the corner of the old lady's cottage.'

b. yaah bi raam pyaarii nae e de diye

this.PL too Ram Piyari DAT PRT give give.IMP

'Give these to Ram Piyari too.'

c. mAn-ne sAhAb-ne mar-a

I-DOM Sahib.M.SG-ERG hit.PRF-M.SG

'The Sahib hit me.'

Haryani (Butt \& Ahmed 2011, 561-562) 
More to the point, there is internal evidence against ergative as an instrumental/agent case from modal constructions expressing necessity. In Punjabi these are based on a non-finite form of the verb traditionally called the infinitive, optionally followed by the auxiliary 'be'. The case and agreement alignment of transitive and unergative Vs is the same as in the perfect. As we can see in (33), the internal argument is in the absolute form and the infinitive agrees with it in number and nominal class; the external argument is in the ergative. What is not expected is that these constructions also present the sole argument of unaccusative Vs (an internal argument) in the ergative, as illustrated in (34); the verb agreement is in the invariable masculine singular - as always when only oblique arguments are present. The evidence in (34) is sufficient in itself to exclude that $-n e$ is connected to the expression of external arguments.

a. mund-e-ne rott-i kha-n-i a/si
boy-OBL.M.SG-ERG bread-ABS.F.SG eat-INF-F.SG be.PRS/be.PST
'The boy is/was to eat the bread.'
b. una-ne dərwaddz-a-e kol-n-a-e
they-ERG door-ABS.M.SG/-M.PL open-INF-M.SG/-M.PL
'They must open the door(s).'
c. mund-e-ne/o-ne dor-n-a/so-n-a $\quad$ (a/si)
boy-OBL.M.SG-OBL/he-OBL run-INF-M.SG/sleep-INF-M.SG be.PRS/be.PST
'The boy/he has/had to run/sleep.'
(34) a. mund-e-ne/mund-ea-ne o-n-a/ dig-n-a
boy.OBL.M.SG-ERG/boy-OBL.M.PL-ERG come.INF-M.SG fall-INF-M.SG
'The boy/the boys must come/fall.'
b. kur-i-ne/ kur-ĩã-ne o-n-a/ dza-n-a
girl-F.SG-ERG girl-F.PL-ERG come-INF-M.SG go-INF-M.SG
'The girl/the girls must come/fall.'

The idea that ergative may be an instrumental/agent case strictly connects to the traditional idea that the perfect is passive-like, hence essentially a voice phenomenon. This idea is endorsed also by Baker and Atlamaz (2013), writing on Kurmanji Kurdish, though they otherwise assume that the oblique subjects seen in the perfect are simply defaults. Yet, apart from any theoretical consideration, in Punjabi the passive, illustrated in (35), has quite a different organization from the perfect. ${ }^{16}$ Specifically, perfect

${ }^{16}$ Passives in Punjabi typically involve the auxiliary ge- 'go'. In (35) we display an especially elementary example, sufficient to make the point in the text. 
and passive are seen to have lexicalizations that are not even partially overlapping, since the verb in (35) is in the root form (from which the infinitive is formed). Furthermore, the agent is introduced by the postposition -to, excluding any semantic link between ergative -ne and by-phrases.

(35) aval-i kita:b sar-e mund-ea-to

that-F.SG.ABS book.F.SG.ABS all-M.PL boy-M.PL.OBL-by

hameja par hun-d-i a

always read.INF be-PROG-F.SG be.PRS

'That book is always being read by all the boys.'

Rather, both the data and reasons of simplicity and naturalness lead us to conclude that the literature drawing a close parallel between ergativity and possession is on the right track, at least in Indo-Iranian (for Kurdish, see section 4). According to section 3.1, the inclusion/possessor category $(\subseteq)$ is lexicalized as -de (the descriptive genitive) when embedded in DPs and as - $n u$ (the descriptive dative/DOM) when embedded under VP. In terms of the connection between ergativity and possession, we expect the same category $(\subseteq)$ to characterize -ne, i.e., the descriptive ergative. Let us focus on perfects. If we combine the proposed characterization for the ergative argument with the structure of the perfect VP in (10), we obtain (36) as the structure for example (5b). We again treat $(\subseteq)$ as an elementary predicate, with two argument places. The argument 's/he', to which $(\subseteq)$ morphologically attaches is interpreted as including (locating etc.) a state, represented by the VP ('eaten the bread'); the latter is effectively the second argument of $(\subseteq)$. In other words, in these languages we can identify the descriptive ergative with the $(\subseteq)$ predicate, embedded VP-externally (in VP-adjoined position).

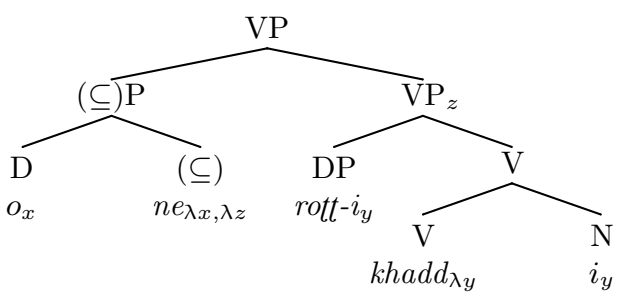

The configuration underlying perfects with unergative Vs is essentially the same as in (36). Specifically, the external argument is attached to the predicative core via the ergative postposition -ne, corresponding to $(\subseteq)$, as shown in (37) for example (12b). In the absence of any internal argument 
the perfect participle of unergative Vs surfaces with an invariable masculine singular inflection -(e)a.

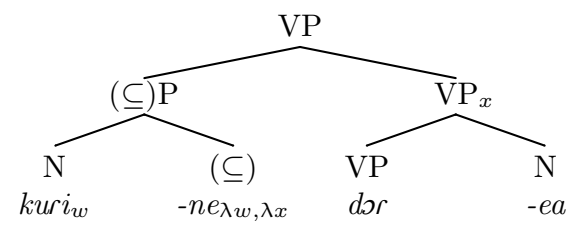

In the discussion at the end of section 2.1, we suggested two possible ways of dealing with invariable inflections. In standard minimalist terms, one may say that in the absence of suitable goals the probe is checked by default - and realized as the morphophonological Elsewhere. On the other hand, the conception of unergative Vs as concealed transitives initiated by Hale \& Keyser's (1993), suggests a possible alternative. For, if unergatives involve a two-tiered structure, consisting of a nominal(-like) root and of a light verb, one could say that in (37) the invariable inflection matches the incorporated object. This second alternative is a way to maintain the idea that all agreement inflections have an interpretable content (or are checked by an interpretable content), and therefore to be preferred in present terms.

Control structures of the type in (38)-(40) bring to the fore the fact that in progressive tenses PRO is bound by the matrix [Spec, Asp] (hence by a nominative, in terms of abstract case), as in (38)-(39). In perfect tenses, for instance in (40), it is bound by the ergative argument. The embedded verb is the same form that shows up in necessity contexts, i.e., the infinitive, behaving very much like an English infinitive. For ease of processing we have enclosed the embedded control sentence between square brackets. The internal organization of the control ("infinitive") sentence is parallel to that seen in the necessity examples (33)-(34). With transitives, the internal argument may be introduced in the absolute form - and the verb agrees with it, as in $(38 \mathrm{a}-\mathrm{b})$ and (40). ${ }^{17}$ If the internal argument is introduced by the DOM oblique $n u$, as in (38c), the infinitive has

${ }^{17}$ Latin has a so-called gerundive, which is an irrealis, with a necessity reading, deontic or epistemic in examples like (i). Like the Punjabi infinitive, the Latin gerundive agrees with the internal argument of a transitive as in (ia), while it is in an invariable form with intransitives (ib). As in Punjabi, the external argument of transitives and the internal argument of unaccusatives appear in an oblique case. Lacking the specialized ergative, Latin resorts to the all-purpose oblique, i.e., the dative:

(i) a. Carneadea nobis adhibenda divisio est Carneades' us(DAT) to.be.used division is 'We must use Carneades' division.'

(Cicero, De Finibus, 5.16.4) 
the invariant masculine singular inflection - as it does in the intransitive contexts in (39). ${ }^{18}$

(38) a. o $\quad[$ kur-i dekh-n-i $] \quad$ t $\int \supset n-d-a / i$

s/he.ABS girl-F.SG.ABS see-INF-F.SG want-PROG-M.SG/F.SG

'S/he wants to see a girl.'

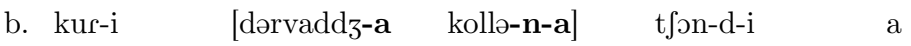

girl-F.SG.ABS door-M.SG.ABS open-INF-M.SG want-PROG-F.SG be.PRS

'The girl wants to open the door.'

c. me: [mund-e-nu/kur-i-nu dekh-n-a] tృon-d-i a

I.ABS(F) boy-M.SG.OBL-OBL/girl-F.SG-OBL see-INF-M.SG want-PROG-F.SG be.PRS

'I want to see the boy/the girl/you.'

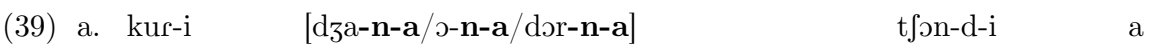

girl-F.SG.ABS go-INF-M.SG/come-INF-M.SG/run-INF-M.SG want-PROG-F.SG be.PRS

'The girl wants to go/to come/run.'

b. mund-e [dig-n-a/dər-n-a] tfon-d-e a

boy-M.PL.ABS fall-INF.M.SG/run-INF-M.SG want-PROG-M.SG be.PRS

'The boys want to fall/run.'

(40) o-ne sottf-ea (a) [kita:b par-n-i]

s/he.OBL think.PRF.M.SG be.PRS book.ABS.F.SG read.INF.F.SG

'S/he thought of reading the book.'

b. hominibus moriendum est enim omnibus

men(DAT) to.die is indeed all(DAT)

'All men must indeed die.' $\quad$ (Cicero, Tusculanae Disputationes, 1.9.15)

18 The infinitive of Punjabi is similar to the English gerund in several respects. First, that Punjabi infinitives are nominal is confirmed by the fact that they can bear their own case marking (with an invariant masculine singular inflection), for instance the - nu case in (i), cf. (40). The fact that they still take an absolute internal argument confirms that they have an inner VP level of structure.

(i) o-ne sottf-ea (a) [kita:b par-n-e-nu]

s/he.ERG think.PRF-M.SG be.PRS book.ABS.FSG read-INF-OBL.M.SG-OBL

'S/he thought of reading the book.'

Like -ing in English, it is natural to surmise that the infinitive inflection in Punjabi is a nominalizer (Nom). But precisely because of the complex issues connected to nominalizing verb morphology (English -ing), an account of their internal structure (hence of the role of ergative arguments within it) is beyond the scope of the present article. 
As it may be expected, reflexives return the same results as control, i.e., the reflexive in (41) can equally be controlled by the absolute external argument in $\left(41 \mathrm{a}-\mathrm{a}^{\prime}\right)$ or by the ergative one in $(41 \mathrm{~b})$. Note that in the progressive $\left(41 \mathrm{a}-\mathrm{a}^{\prime}\right)$ the reflexive agrees in phi-features with the absolute form, while with ergative external arguments in (41b), the reflexive appears in an invariable form coinciding with the feminine singular.
(41) a. kur-i
appe-i kita:b
par-d-i
a
girl-F.SG.ABS self-F.SG book.F.SG.ABS read-PROG-F.SG be.PRS
'The girl is reading the book by herself.'
$\mathrm{a}^{\prime}$. mund-a app-e kita:b par-d-a a
boy-M.SG.ABS self-M.SG book.F.SG.ABS read-PROG-M.SG be.PRS
'The boy is reading the book by himself.'
b. mund-e-ne/kur-i-ne appe-i idd-a kitt-a
boy-M.SG.OBL-ERG/girl-F.SG-ERG self-F.SG this-ABS.M.SG do.PRF-M.SG
'The boy/the girl did this by her/himself.'

In short, as much literature on ergativity emphasizes (Aldridge 2008) what appears to be relevant for reflexive binding and control is some notion of outer argument in predicate structure (external argument of transitives, internal argument of unaccusatives), independently of the particular case and agreement alignment determined by aspectual or other factors.

\subsection{Discussion: competing accounts of ergative case}

Our core proposal concerning ergative case is that while progressive sentences have structures like (18)-(20), where the external argument is attached to an Asp verbal layer of structure, perfect sentences have the structure in (36)-(37), where the external argument is attached to the main sentential spine via the ergative case, in reality an inclusion-of-the event elementary predicate.

The crucial characteristic of the perfect is that it denotes a property. Thus perfects introduce the internal argument of the predication; any additional argument, and specifically the external argument, can only be introduced as an oblique. In this respect we share the same outlook as Alexiadou (2001, 172-173), namely that "nominalizations and ergative patterns $[\ldots]$ are reflections of the same structure: one that involves a single theme argument that appears as sister of the lexical root, and an adjunct type of phrase that introduces the agent". We take $(\subseteq)$ to be the fundamental characterization of obliques - hence the ergative argument is ultimately 
a possessor. On the contrary, progressive aspect introduces an eventive organization of the sentence, corresponding to the projection of a further Asp level of structure. In short, the account of Punjabi represented by the progressive structures in (18) vs. the perfect structures in (36) shows that the same predicate-argument complex can be introduced by a twolayered predicate or by a one-layered predicate plus an oblique "case" on one of the arguments (in reality an elementary predicate). In other words, there is not a universal categorial template whose pronunciation is the only possible dimension of variation, since even within the same language, the same argument-predicate structure can be conveyed by different syntactic shapes of predicates.

We have indicated at the beginning of this section that in Punjabi absolute forms are morphologically set apart from other forms, bearing a different stem inflection at least in the masculine, and being followed by case adpositions. In the rest of the section, we have argued that this morphological contrast corresponds to a syntactic difference between direct forms attached directly on the verbal spine (see the discussion in section 2.2 ) and oblique forms, which require the extra predicative content, provided by the so-called case adposition. In this sense, we exclude that ergative is a structural case assigned under the dependent case algorithm of Marantz (1991). Marantz's original idea is that languages dispose of a set of inherent cases, of a dependent case and of an unmarked/default case. In nominative-accusative contexts, the dependent case, i.e., accusative, is assigned to the structurally lower of two arguments not inherently case marked; the other argument is assigned the unmarked case, i.e., nominative. In ergative-absolute contexts, the dependent case, i.e., ergative, is assigned to the structurally higher of two DPs not inherently case marked; the other argument is assigned the unmarked case, i.e., nominative/absolutive.

The data that we have presented from Punjabi also contain one more specific problem for the dependent case view of ergative, since we do not expect ergative to show up on the sole argument of unaccusatives in necessity contexts, as in (33)-(34). For the sake of completeness we shall consider how these data are compatible with the $(\subseteq)$ characterization proposed here. Punjabi infinitives can bear their own case marking (with an invariant masculine singular inflection)-which supports the conclusion that they are nominal. Thus control examples like (38)-(39) alternate with examples like (42a) below, where the infinitive bears the -nu case. Under a different embedding verb ('think' rather than 'want'), the same 
alternation is observed, as in (42b). ${ }^{19}$ The fact that the infinitives in (42) still take an absolute internal argument confirms that they have an inner VP level of structure, very much like English gerunds.
a. o(ho) t $\int 3 n-d-e$
a kita:b
pas-n-e-nu
they want-PROG-M.PL be.PRS book.ABS.F.SG read-INF-M.SG.OBL-OBL
'They want to read the book.'
b. o-ne sottf-ea
(a) kita:b
par-n-e-nu
s/he.ERG think.PRF-M.SG be.PRS book.ABS.F.SG read-INF-OBL.M.SG-OBL
'S/he thought of reading the book.'

We adopt for the Punjabi infinitive a structure in which the infinitival inflection is a nominalizer Nom, as in (43).

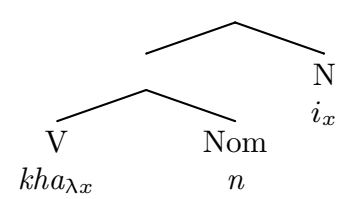

Going back to necessity contexts in (33)-(34), when the morphological structure in (43) is projected onto a syntactic tree, we obtain structures of the type in (44) for the transitive sentence (33a). The Nom layer of structure requires the external argument of the transitive verb to be introduced as an oblique. The internal argument licenced by agreement with the verb, surfaces in the absolute form.

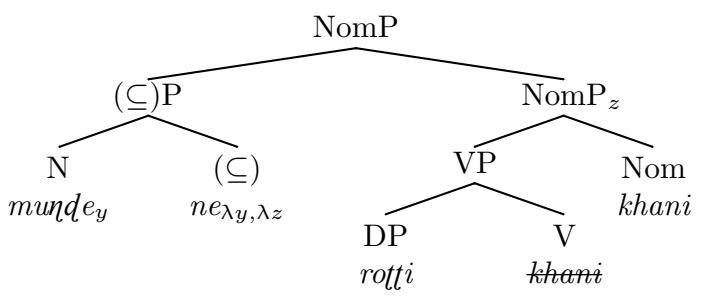

19 The parallelism with Latin again holds. The same verb form that appears in the "gerundive" examples in (40) can be construed with its own case in examples like (i), traditionally called 'gerunds'. In (i) the case on the gerund ('doing') is the genitive, while the object of the gerund ('something') is in the accusative; the gerund bears an invariant neuter singular inflection.

(i) consilium aliquid faciend-i

counsel something doing-GEN

'the decision of doing something'

(Cicero, De Inventione, 1.36.12) 
Unaccusative examples like (34a) have the structure in (45). What must be kept in mind is that in necessity structures, an oblique (ergative) argument is required by the infinitive (or by its deontic reading), so that the sole argument of all intransitives ends up with the same case as the external argument of transitives. The verb inflection takes the invariable (expletive) masculine singular form, as in other instances where only oblique arguments are present in the structure, as discussed around (12).

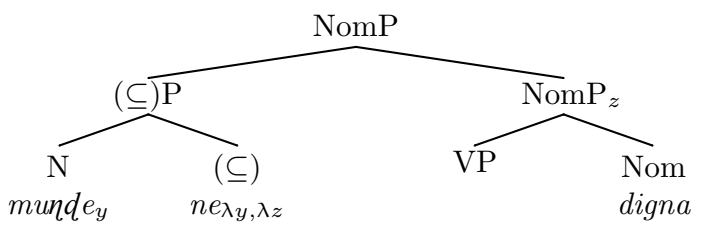

A dependent case approach to the ergative case in (44)-(45) does not work, because it would predict the same sensitivity as in perfects to the external argument status of arguments. Dependent case theorists could of course say, that in (44)-(45) the solution we propose is essentially correct, namely that ergative assignment is an intrinsic property of the infinitive/modal form. However, they would then be forced to recognize that there are two ergative cases, one which is structural and determined by the dependent case algorithm - and one which is inherent.

Bobaljik (2008) and Preminger (2014) argue that the dependent case approach changes the approach to agreement as well. Their idea is in a way the opposite of Chomsky's (2001) - namely that case is primitive with respect to agreement. Which DP agrees with a given head is determined by an accessibility hierarchy of cases, where unmarked cases are maximally accessible, followed by dependent cases and finally by inherent cases (in a fashion similar to the implicational hierarchy assumed in the typological literature, cf. Moravcsik 1978). Empirically, this analysis of agreement facilitates stating certain agreement parameters, for instance the fact that ergatives, which never agree in Punjabi, Hindi, etc., are accessible to agreement in other Indo-Aryan languages, for instance Nepali (Schikowski 2013; Deo \& Sharma 2006). ${ }^{20}$ Furthermore, it facilitates accounting for invariable agreements. When an inflectional head does not find an accessible target - for instance in the double oblique structures exemplified above for Punjabi perfects, the derivation does not crash; rather the morphology in-

${ }^{20}$ Another parameter involves the possibility of agreement with DOM objects - for instance in Marwari the perfect "always agrees with $\mathrm{O}$ whether it is marked [DOM] or not" (Verbeke 2013, 234). 
sures that the relevant inflection surfaces in the default form (masculine singular in Punjabi).

However, these empirical advantages rely on constraints which could be added to any theory - in this sense they do not have an explanatory edge. Even the present article can adopt an accessibility hierarchy of cases in order to facilitate the stating of agreement parameters. In other words, there does not seem to be any special advantage in the accessibility hierarchy of cases with respect to a naked stipulation of the facts, like the VIVA (Visibility of Inherent-Case to Verbal Agreement) parameter of Anand \& Nevins (2006), namely "A language will differ as to whether the verb can agree with an inherently case-marked DP". Similarly, most analyses (including the present one, can incorporate a stipulation to the effect that unchecked agreement inflections (whether uninterpretable or unvalued) do not induce the derivation to crash, but are repaired by a default setting, as was already suggested in the discussion surrounding (37). Yet we also tried to suggest a more principled solution. In the Punjabi perfect, invariable agreement is restricted to unergative verbs - or to transitive verbs with DOM objects which as part of the present analysis we construe as true datives, yielding an unergative configuration. Our proposal is that in these contexts the invariable masculine singular inflection of the verb matches the incorporated internal argument of the unergative (with reference of Hale \& Keyser's 1993 lexical decomposition of these verbs).

\subsection{The Person split}

Another aspect of the syntax of Punjabi not dealt with so far needs to be explicitly investigated, namely the person split observed within the perfect, whereby 1 st $/ 2$ nd person $(1 / 2 \mathrm{P})$ external argument are found in the absolute form, rather than in the ergative case obligatory with 3rd person referents, as illustrated in (46) with transitive verbs and in (47) with an unergative $V$. The same Person split extends to the other context where ergative is lexicalized on 3rd person referents, namely the modal necessity context constructed involving the infinitive, as illustrated in (48).

(46) a. me: kita:b/kitabb-a

pər-i/-1̃ã

si

I.abs book.F.SG.ABS/book-F.PL.ABS read.PRF-F.SG/-F.PL be.PST

'I read the book/books.'

b. me:/o-ne/mund-e-ne

(ek) pətthərə

dekkh-ea/-e

I.ABS/he.ERG/boy-OBL.M.SG-ERG (a) stone.ABS.M.SG/M.PL see.PRF-M.SG/-M.PL 'I/he/the boy saw a/the stone/(the) stones.' 
c. appa/tusi mund-e dekkh-e si we.ABS/you.PL.ABS boy-ABS.M.PL see.PRF-M.PL be.PST 'We/you saw the boys.'

(47) $\mathbf{m \varepsilon :}$ /appa boll-ea si

I.ABS/we.ABS talk.PRF-M.SG be.PST

'I talked.'

(48)
me: $/$ tu:/appa
so-n-a/dər-n-a
$\mathrm{a} / \mathrm{si}$

I.ABS/you.ABS/we.ABS sleep-INF-M.SG/run-INF-M.SG be.PRS/PST

'I/you/we have/had to sleep/run.'

The fact that the $1 / 2 \mathrm{P}$ external argument appears in the absolute form does not change the agreement alignment of perfects (or of necessity forms). In transitive examples like (46), the perfect agrees with the internal argument, while with unergative Vs in (47)-(48) it bears the invariable masculine singular agreement. The same is true in transitives where the internal argument is introduced by the DOM oblique element $-n u$, as in (49).

(49) $\mathbf{m \varepsilon :} / \mathbf{a p p a} / \mathbf{t u :} /$ tusi

o-nu/una-nu dekkh-ea

I.ABS/we.ABS/you.ABS/you.PL.ABS him-OBL/they-OBL see.PRF-M.SG

'I/we/you saw him/them.'

From the present point of view, all aspects of the structure of examples (46)-(49) must be as already detailed for other perfects in (36)-(37) - except that the external argument is not associated with the $(\subseteq)$ elementary predicate in terms of which we model ergative case. Putting together the structure of the transitive predicate in (36) with the absence of $(\subseteq)$ ergative case on the external argument, we obtain a structure of the type in (50) for example (46a). In (50) we adopt the conclusion that Participant arguments have a distinct categorial signature, as in much cartographic literature (Bianchi 2006).

(50)

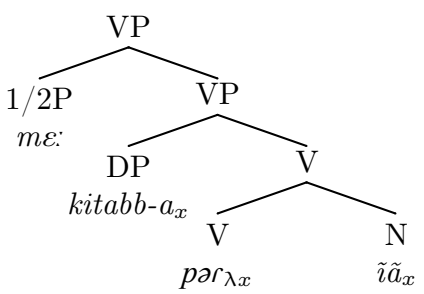

The question is how in (50) the absolute $1 / 2 \mathrm{P}$ form is licenced syntactically and interpretively as an external argument - or vice versa why a 
$(\subseteq)$ ergative case is necessary to licence $3 \mathrm{P}$ arguments in (36). There are several types of answer in the literature, relying directly on the referential properties of $1 / 2 \mathrm{P}$ arguments, i.e., on their Participant vs. non-participant status (person and non-person for Benveniste (1966)), or relying on the structural representations they give rise to, or finally leaving the whole matter to morphological default.

Dixon $(1979,85-86)$ bases his classical discussion of split ergativity on the 'potentiality of agency' scale, i.e., 1st person-2nd person-3rd person-Proper name-Human-Animate-Inanimate. According to Dixon, "it is plainly most natural and economical to 'mark' a participant when it is in an unaccustomed role. [...] A number of languages have split case-marking systems exactly on this principle: an 'ergative' case is used with NP's from the right-hand end, up to some point in the middle of the hierarchy [...]". Nevertheless DeLancey (1981) observes that languages with so-called ergativity splits, i.e., alternations between the ergative/absolutive case system and the nominative/accusative system, most commonly oppose 1st and 2nd person to 3rd. De Lancey's (1981) explanation is based on notions of attention flow and view point - rather than potential agentivity. The attention flow proceeds from agent to patient in a transitive event. On the other hand, there are at least as many viewpoints as participants in the event. If a speech act participant, SAP, is also a participant in the event, the most natural point of view is the one associated with it. Thus in split ergative systems, if the starting-point of the attention flow "is also an SAP, i.e., a natural viewpoint locus, it is so marked by being in the nominative case. Otherwise it must be marked for ergative case, which identifies it as the natural starting-point" (ibid., 640).

Nash $(1995 ; 1997)$ is among early proponents of the encoding of person splits in terms of syntactic hierarchies. In analysing the person ergativity split in Georgian, she concludes that agents in ergative languages correspond to a predicate-internal position, although they are projected to the Spec of a higher category in non-ergative languages. For Nash the definite character of $1 / 2 \mathrm{P}$ pronouns means that they will be "licenced higher than other pronominal arguments, at a level at which the ergative/absolutive patterns is blocked" (Nash 1997, 137). In other words, 1/2P structures are "bigger" than 3P ones - exactly like progressive structures are bigger than perfect ones. More recently, Coon and Preminger $(2012,316)$ propose that "the presence of a 1st/2nd-person pronoun in the clause thus necessitates the presence of a corresponding functional projection [...] this functional projection - call it ParticipantP - disrupts the case calculus [...] The result would be that in a language that was normally ergative, the presence 
of a 1st/2nd-person pronoun would result in a 'shift' out of the normal ergative pattern in exactly the same way outlined above for aspect-based splits [...] regardless of whether a case-competition or Probe-Goal system is adopted". Reference to aspect-based splits assumes an analysis along the lines of Coon (2013); in addressing it in we have indicated that Punjabi offers no empirical evidence for the analysis of progressive sentences based on the presence of an extra auxiliary. ${ }^{21}$

Legate $(2014,186)$ supports a morphological approach on the basis of strictly empirical evidence. As she notes, "on a syntactic analysis, a DP without ergative case is expected to trigger non-ergative case agreement - the DP was not assigned ergative case and so cannot trigger ergative case agreement. On a morphological analysis, a DP without ergative case can trigger ergative case agreement - the DP is assigned ergative case, but this case is not morphologically realized". In the ergativity split languages considered by Legate, the relevant tests come out against the syntactic approach. The same results can be replicated for the Punjabi perfect. In $\left(51 \mathrm{a}-\mathrm{a}^{\prime}\right)$, a $1 / 2 \mathrm{P}$ external argument is coordinated with a $3 \mathrm{P} \mathrm{DP}$, the latter displays ergative case marking. In $\left(51 \mathrm{~b}-\mathrm{b}^{\prime}\right)$ a $3 \mathrm{P}$ DP used as an appositive modifier to a $1 / 2 \mathrm{P}$ external argument, is equally associated with ergative case.

(51) a. me: te mund-e-ne kita:b pər-i

I and boy-OBL.M.SG-ERG book.F.SG.ABS read.PRF-F.SG

rott.t-i khadd-i

bread-ABS.F.SG eat.PRF-FSG

'I and the boy have read the book/eaten the bread.'

$\mathrm{a}^{\prime}$. tu: te kur-i-ne kita:b pər-i rott-i khadd-i

I and girl-F.SG-ERG book.F.SG.ABS read.PRF-FSG bread-ABS.F.SG eat.PRF-F.SG

'You and the girl/the boys have read the book/eaten the bread.'

${ }^{21}$ Coon and Preminger also draw a parallel between their account of Person ergativity splits and accounts of auxiliary selection according to Person in Central and Southern Italian dialects by Kayne (1993); Cocchi (1995; 1998); D'Alessandro \& Roberts (2010). For these authors, have auxiliary in the 3P depends on an abstract preposition ('to') incorporating into be; ParticipantP forms a barrier to this incorporation and be auxiliary surfaces in the $1 / 2 \mathrm{P}$. However, Legendre (2010), Manzini and Savoia $(2005 ; 2011 \mathrm{a})$ show that there are varieties where the person split pattern is maintained $(1 / 2 \mathrm{P}$ vs. $3 \mathrm{P})$ - but the auxiliaries are inversely matched $(1 / 2 \mathrm{P}$ with have and $3 \mathrm{P}$ with $b e$ ). Such data suggest that the person split and auxiliary selection really are two independent variables, which can freely recombine. A strong theory enforcing the 'standard' auxiliary split (i.e., $1 / 2 \mathrm{P}$ with be and $3 \mathrm{P}$ with have) appears to undergenerate. 
b. me: sab to tyang-i kur-i-ne kita:b pər-i

I the most good-F.SG girl-F.SG-ERG book.F.SG.ABS read.PRF-F.SG

'I, the best girl, read the book.'

$\mathrm{b}^{\prime}$. tu sab to tayg-a munde-ne kita:b pər-i

you the most good-M.SG boy-OBL.M.SG-ERG book.F.SG.ABS read.PRF-F.SG

'You, the best boy, read the book.'

From facts like those in (47) Legate $(2014,203)$ concludes that "for a subset of nominal types, morphological realization of the ergative is syncretic with the morphological realization of the nominative", where syncretism is accounted for in a canonical DM framework via Impoverishment of the Erg feature on Participant arguments. Similarly, Keine (2010) and Keine and Muller (2009) account for the person split of Punjabi and Marathi, by assuming an Impoverishment operation, which deletes [-oblique] for participant subjects regardless of aspectual features. These accounts have the same problems generally imputed to Impoverishment based analyses (Manzini \& Savoia (2007); Kayne (2010) on Romance clitics) - namely that the matching of underlying and surface forms is entirely arbitrary. In other words, the theory equally has the power to delete ergative/oblique on non-Participant arguments.

The empirical arguments in (51) advise against a structural encoding of the Person ergativity split. Contrary to Legate, we do not infer from this that morphology must be responsible for the pattern. There is an obvious alternative, suggested by classical discussions such as DeLancey's - namely that although the absence of an ergative case on the $1 / 2 \mathrm{P}$ argument in (50) is a lexical fact about $1 / 2 \mathrm{P}$ pronouns, it is not justified by morphological readjustments but rather by interpretive considerations.

In present terms, the question is why the attachment of $1 / 2 \mathrm{P}$ in the structure in (50) can take place by simple argument application (via a lambda-operator) without the support of an oblique elementary predicate - or conversely why simple lambda-attachment of the external argument is not available with $3 \mathrm{P}$, forcing recourse to ergative case marking (in present terms $(\subseteq)$ ). We propose that the interpretation of Participants arguments, crucially based on their direct anchoring to the universe of discourse, can dispense with specialized means of attachment to the structure of the event, specifically with ergative $(\subseteq)$, because of their intrinsic ability to serve as 'inclusion/location-of-event'. By contrast, 3P referents require a specialized morphosyntactic characterization of their role in events. ${ }^{22}$

${ }^{22}$ Because of the parallel that the article draws with possessed DPs, an anonymous reviewer wonders whether a $1 / 2$ vs. 3 split manifests itself in DPs as well - specifically, 
This proposal has less deductive depth than structural approaches of the type suggested by Coon and Preminger (2012), which however prove too strong face to empirical evidence, cf. (51) and footnote 21. At the same time, it differs from morphological approaches of the type entertained within DM. A morphological analysis along the lines of Legate (2008) assumes that impoverishment rules undo the underlyingly regular structures fed to them by syntax, where abstract ergative case is assigned to $1 / 2 \mathrm{P}$ as well. The present proposal says that merger of $1 / 2 \mathrm{P}$ with $(\subseteq)$ does not take place at all, because of the inherent association of $1 / 2 \mathrm{P}$ with the 'possessor' role. Thus under morphological Impoverishment, $1 / 2 \mathrm{P}$ and $(\subseteq)$ are incompatible for arbitrary reasons of lexicalization/pronunciation. Under the present approach, $1 / 2 \mathrm{P}$ and $(\subseteq)$ are in fact intrinsically connected in the conceptual component - nor could there be a language where it is rather $3 \mathrm{P}$ that is so connected.

\section{The "decay of ergativity"}

In what follows we will consider how the continuity, or discontinuity, between forms of aspectual split in Iranian languages and in Indo-Aryan (here Punjabi) can be captured within the present framework of assumptions. Many Iranian languages (though not Persian) are characterized by the contrast between a nominative alignment in the imperfective and an ergative alignment in the perfect. We already saw in relation to the Indo-Aryan language Haryani in (32) (Butt \& Ahmed 2011) that ergativity splits can be observed in the absence of a specialized ergative case; indeed in Haryani the subject of perfect sentences is introduced by an all-purpose oblique (dative). Kurmanji Kurdish is characterized by an even more elementary case organization, since it has just two possible forms for DPs, best characterized as an absolute form and an oblique one. Thus in the ergative alignment, the external argument of transitives surfaces in the all-purpose oblique of the language, which also characterizes possessors within DPs (genitives) and VPs (datives). An even more residual case system is found in Sorani Kurdish, where DPs lack case inflections and the ergativity split has a reflex only in the lexicalization of oblique clitic pronouns, which nevertheless in the ergative alignment lexicalize the external argument of transitives.

in the form of case. We pointed out that a person split is found in genitives (i.e., DPinternal possessors), as illustrated in (26a), where the 3P argument is affixed by -de, vs. (26b), where the Participant argument is affixed by -re (cf. also fn. 13), though we are not able to provide any further insight on this. 


\subsection{Kurmanji Kurdish: the perfect and the active/ergative parameter}

Kurmanji Kurdish (for a general description see Thackston 2006a) has a case system which distinguishes an absolute form (conventionally the nominative) from an oblique one. In nouns, the traditional nominative case corresponds to the uninflected lexical base, therefore to what we have called the absolute form of the noun; in the glosses and in the discussion we shall keep the term 'nominative' for descriptive ease. A case and agreement alignment split is observed in Kurmanji as in Punjabi. In the present, the absolute/nominative form lexicalizes the external argument of transitive verbs, as in (52), and the sole argument of intransitives, as in (53); the verb agrees with this argument in person and number. The internal argument of transitives in (52) is in the oblique case. ${ }^{23}$

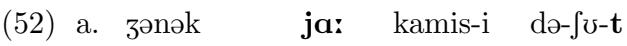

woman.NOM LKR.F shirt-OBL PROG-wash-3SG

'The woman is washing the shirt.'

b. $\quad$ z $\quad$ kurk-(æk-)i/ket jk-(æk-)e je:/ja: də-bin-ım

I.NOM boy-(INDF)-OBL/girl-(INDF)-OBL LKR.M/F PROG-see-1SG

'I(f./m) am seeing the/a boy/girl.'

c. $\varepsilon \mathrm{Z}$ ja: tæ də-bin-Im

I.NOM LKR.F you.OBL PROG-see-1SG

'I(f.) am seeing you.'

d. tu je: mən də-bin-i

you.NOM LKR.M me.OBL PROG-see-2SG

'You(m) are seeing me.'

(53) $3 ə n ə k \quad$ ja: də-nəv-it

woman.NOM LKR.F PROG-sleep-3SG

'The woman is sleeping.'

In the perfect, a different, ergative alignment prevails. The internal argument of transitives in (54) and the sole argument of intransitives in (55) show up in the absolute/nominative form, with which the verb agrees in person and number. The external argument of perfect transitives is lexical-

${ }^{23}$ Our data come from the Bahdînî dialect (see footnote 1) which has a system of "tense ezafes" (Haig 2011) glossed here as linkers (Lkr); these are effectively "subject clitics" agreeing with the subject in the absolute form (Franco et al. 2015). Since we take the linker to be a subject clitic, we assume its position to be within the T field of the sentence, and we correspondingly do not assign it a position in structure (62) below. 
ized by the oblique. Unlike what we saw in Punjabi, there is no difference between unaccusative and unergative contexts; in other words, in intransitive perfects like (55) the case and agreement alignment is not sensitive to the internal vs. external argument divide.

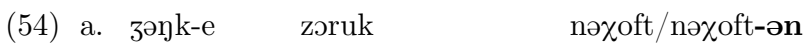

woman-OBL child/children.NOM cover.PRF-3SG/-3PL

'The woman covered the child/the children.'

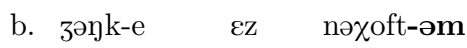

woman-OBL I.NOM cover.PRF.1SG

'The woman covered me.'

c. mən korek dit-ən

I.OBL boys.NOM see.PRF.3SG

'I saw the boys.'

(55) a. av kaft

he.NOM fall.PRF.3SG

'He fell.'

b. tu nəvəst-i/ar nəvəst

you.NOM sleep.PRF.2SG/he.NOM sleep.PRF.3SG

'You have slept/he has slept.'

The traditional characterization of the case inflections $-i$ for masculine singular, $-e$ for feminine singular and - $a$ for plural as obliques is supported by the fact that they alone can lexicalize goal (thematic) datives, as in (56). Similarly the possessor in the DP in (57), is in the oblique (genitive); an ezafe, i.e., a linker, is also present, agreeing with the head noun. Finally, the oblique appears as the internal argument of Prepositions, as in (58).

(56) a. av je: partuk-e də-da-ta zəクk-e he.NOM LKR.M book-OBL PROG-give-3SG woman-OBL

'He is giving the book to the woman.'

b. $\varepsilon z \quad$ ja: qalam-i de-da-ma kurk-a:/ket fk-a:

I.NOM LKR.F pen-OBL PROG-give-1SG boys-OBL/girls-OBL

'I are giving the pen to the boys/girls.'

(57) dest-e ket $\int k-e$

hand-LKR.M girl-OBL.F

'the hand of the girl' 


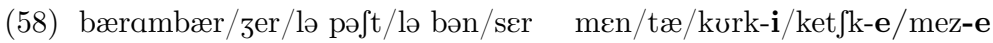
in front of/under/behind/before/on me.oBL/you.oBL/boy-oBL/girl-oBL/table-OBL 'in front of/under/behind/before/on me/you/the boy/the girl/the table'

A descriptive difficulty arises in connection with the exact characterization of the verb forms seen in the nominative alignment in (52)-(53) and in the ergative alignment in (54)-(55). The literature generally refers to the Kurdish split as a present vs. past tense one. Verbs display two stems, each of which forms the basis for a full set of tenses, e.g., bîn in $(52 \mathrm{~b}-\mathrm{d})$ vs. dît in (54c) for 'see'. As Baker and Atlamaz (2013) point out, the "imperfective" prefix $d \imath^{-}\left(d{ }^{-}\right)$can attach to a past stem, yielding a "past imperfective". Still, sentences containing this form of the verb present the ergative alignment, as shown in (59).

(59) Ml di-kir.

I.OBL PROG-do.PST(3SG)

'I was doing (it), used to do (it).'

Imputing the nominative and ergative alignments observed in Kurmanji to a temporal (past vs. non-past) split, as implied by the traditional terminology, raises considerable problems within the framework of assumptions about ergativity, which characterizes not only the present approach - but also practically any other generative analysis we mentioned. Syntactically and interpretively, T composes with a full event, as schematized in (21) for Punjabi. Therefore we do not expect $\mathrm{T}$ to be able to determine different internal shapes of the predicate - as is fundamental to current accounts of aspectual splits. Baker and Atlamaz propose an analysis based not on the category $\mathrm{T}$, but on the category Voice. They construe the present form as bearing active voice and implying a phasal vP; vice versa the past form is passive and corresponds to a non phasal $\mathrm{vP}^{24}$ When it comes to the connection between active and passive Voice and T, they only offer the comment that "it seems common to associate passive voice value with past tense value and active voice value with present tense value, at least in IE languages, although we do not know exactly why this is so" (Baker \& Atlamaz 2013, fn. 24).

${ }^{24}$ Baker and Atlamaz provide an example of a Kurmanji passive (actually what they call a quasi-passive) involving the perfect form of the verb, but as they show, the latter is endowed with a nominalizing suffix. Suffixation of the perfect is also necessary for the formation of passives for instance in the Western Iranian language Masali (Paul 2011, 117). 
Given the (conceptual) difficulties with both the traditional $\mathrm{T}$ construal of the Kurdish split and the Voice construal of Baker and Atlamaz, it seems worth investigating what happens if we assume that the ergativity split of Kurmanji has the same basic shape as that of Punjabi. We shall return to the problematic evidence in (59) at the end of this section. Thus we maintain that the organization of the predicate is simpler in the perfect, which in present terms corresponds to a VP. In the transitive perfect in (60) (cf. example (54b)), the agreement on the verb targets the internal argument, which surfaces in the absolute/nominative form. In the absence of an Asp layer, the external argument is introduced by the elementary predicate $(\subseteq)$, denoting a relation between the argument itself and the $\mathrm{V}(\mathrm{P})$ event, as in (60).

(60)

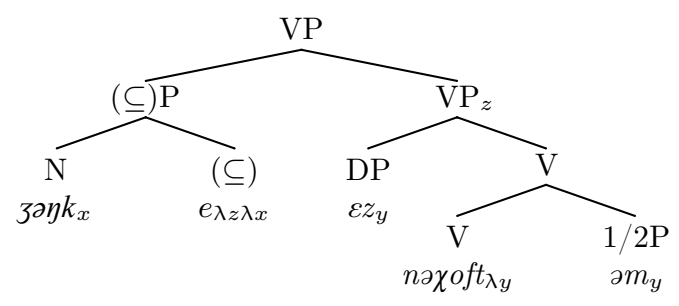

Kurmanji however differs from Punjabi in that it treats all intransitive perfects alike, independently of whether their sole argument is an external argument (unergatives) or an internal argument (unaccusatives). We schematize the unergative case and agreement alignment in structure (61), for sentence (55b). In (61), the verb agrees with the closest argument, which is the sole argument present, as it would be with an unaccusative predicate. In turn, the argument is in the absolute form licenced by local attachment at the $\mathrm{V}$ head without need for an oblique $(\subseteq)$ element.

$(61)$

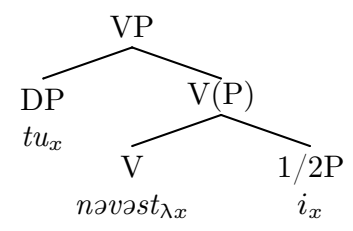

In typological terms, Kurmanji perfects present a classical ergative alignment, which opposes the external argument of transitives (surfacing in the ergative) to other arguments (the internal argument of transitives and the sole argument of all intransitives, agreeing with the verb). Vice versa, even though in the discussion that precedes we have consistently referred to Punjabi perfects as ergative, they rather represents an example of a so- 
called active alignment - opposing internal arguments (of transitives and unaccusatives, agreeing with the verb) to external arguments (of transitives and unergatives).

Baker $(2015,288)$ reports Comrie's (2005) conclusion that only 4 out of 190 languages he considers have the active-inactive alignment (including Basque and Georgian but no Indo-Aryan languages), and goes on to state that "true systematic active-inactive case systems are very rare, may be even unattested". For Baker, this is as it should be, since "dependent case assignment in particular considers whether an NP is higher or lower than another NP in the same domain [...] Similarly Agree typically cares which argument is closest to the case-assigning functional head", predicting that external arguments of transitives will be singled out as bearing the ergative case (either as a dependent case or as a consequence of agreement with a functional projection of V). However, our Punjabi data point to an active alignment; similarly, Butt and Deo (2001) state that "as far as we know, all the Indo-Aryan languages which have an ergative case fall under the 'active' type of language". The active vs. ergative parameter does not have a standard generative treatment, as far we can tell.

There is no problem in standard minimalist terms with ergative Kurmanji perfects. Agreement in the perfect picks the closest argument, which is the sister argument in (60) and the sole argument in (61). Ergative case is necessary only when the embedded predicate already supports an internal argument. The problem is Punjabi. In fact, the perfect alignments of the two languages differ only with unergatives - unsurprisingly, since in Hale and Keyser's (1993) analysis, the latter have a somewhat intermediate status between unaccusatives and transitives. One could assume that in Punjabi and other active languages, the incorporated object maintains a degree of syntactic visibility, inducing unergatives to be computed as transitives. Thus abstract agreement takes place with the incorporated argument, surfacing as an invariable 3rd person singular inflection, as we have suggested already in section 2.1 , while the non-incorporated argument needs ergative case.

\subsection{Kurmanji Kurdish: the imperfective/progressive}

Let us turn to sentences built on the non-perfect/imperfective verb base, beginning with transitives again. If we apply to them the same analysis as for the Punjabi progressive, we obtain structures like (62) for example (52b) (see also footnote 23). Assuming that the verb inflection composes with Asp (or the V-Asp complex), we expect that it will agree with the 
outer argument of the predicate, i.e., the external argument in a transitive or unergative structure or the internal argument if the verb is unaccusative. In this respect, therefore, Kurmanji poses no difficulty, replicating the pattern already studied for Punjabi.

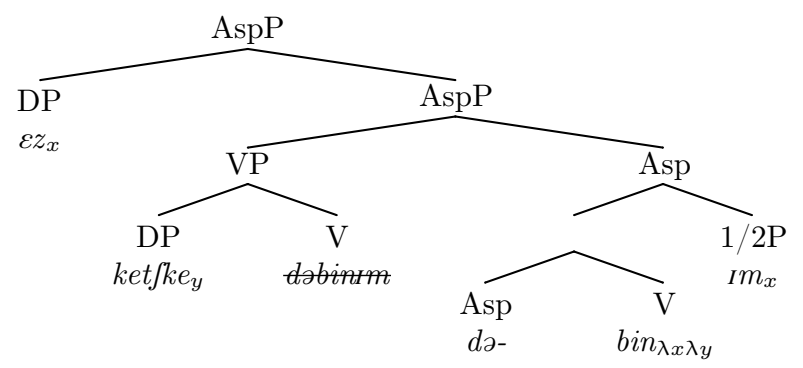

There is however a further important difference between the two languages, concerning oblique case. Recall that in Punjabi a definite/specific internal argument surfaces in the oblique (dative) case $-n u$, both in perfect and in progressive sentences, because of DOM. In Kurmanji the distribution of oblique internal arguments is altogether different, since there is no DOM. In other words all DPs pattern alike independently of their referential saliency - and oblique internal arguments characterize all and only imperfective sentences, as in (62).

According to Baker and Atlamaz (2013), the distribution of absolute/nominative forms is governed by agreement (as proposed by Chomsky 2001) - and they treat the oblique (or objective) case as a default. In section 2.2 , we already pointed out that we are non-committal with respect to absolute forms; specifically, nothing prevents us from assuming that in Kurmanji (though possibly not in Punjabi, cf. section 2.2), they bear a nominative case parasitic on Agree. ${ }^{25}$ However, there are reasons both interpretive and morphological why the oblique case cannot be a default. Interpretively, the oblique case in contexts like (56)-(58) introduces a possession (dative, genitive) relation between the head predicate and a complement. In other words, if there is a default case interpretively, this must surely be the nominative/absolute. Morphology matches interpreta-

${ }^{25}$ Agreement-based and dependent case algorithms may in principle alternate on a parametric basis, allowing the latter to work in Punjabi progressives (cf. Baker \& Vinokurova 2010 vs. Baker \& Atlamaz 2013). Alternatively, since absolute forms bear no evidence of case marking one may assume that agreement is sufficient to licence argument attachment in Kurmanji - however this would imply the abandonment of the Case Filter. 
tion - since it is the oblique that is morphologically instantiated, while the nominative/absolute corresponds to the bare nominal base.

Descriptively, Baker and Atlamaz's recourse to default captures the fact that agreeing absolute/nominative forms and oblique forms are in perfect complementary distribution in Kurmanji. ${ }^{26}$ However, we see no explanatory advantage in evoking the notion of default, rather than simply stating that argument attachment in Kurmanji is satisfied either under agreement with a verb inflection (eventually checking nominative case) - or under (oblique) case assignment. Independent properties of Kurmanji (i.e., no agreement with oblique case) insure that the two conditions will apply disjunctively.

On the other hand, adopting the view that the case seen on the object in (62) is a real oblique commits us to saying that it is attached through the $(\subseteq)$ case/elementary operator. We must then impute to (62) the same interpretation already outlined for Punjabi DOM objects - namely adopting the Hale and Keyser (1993) characterization of transitives as resulting from the incorporation of an elementary (nominal) predicate into a light verb, the internal argument is treated as a possessor of the incorporated (nominal) predicate, as in (63). Since retreating into the assumption that the oblique is a default or Elsewhere case has the problems already noted, we leave things as they stand.

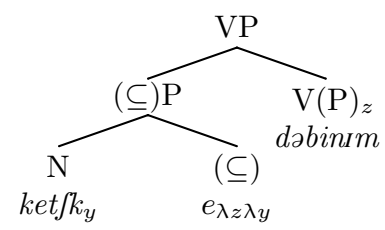

At this point, it remains for us to provide an analysis, however schematic, for sentences like (59), where what we have characterized as the perfect form of the verb is prefixed by the $d \imath^{-}\left(d_{2}-\right)$ morphology, yielding a habitual or progressive interpretation. In (62) we have tentatively identified $d \imath^{-}\left(d \partial^{-}\right)$with the Asp category responsible for introducing the external

${ }^{26}$ However in the variety of Muş the internal argument of transitive perfects is oblique, while the verb surfaces in the 3rd person singular, which yields a double oblique structure; the same is possible in the variety of Dyarbarkir (Dorleijn 1996), as in (i). In themselves, data like (i) are not problematic, since they can be accounted for like the double obliques of Punjabi; they obviously require the invariable 3rd person singular inflection to be available.

(i) We min dit

2PL.OBL I.OBL see.PRF

'You saw me.' 
argument in non-perfect forms. However, Thackston (2006a) shows that $d \imath$ - is in complementary distribution with the prefix $b \imath$ - whose nature is clearly modal (subjunctive). Furthermore in the present (though not in the past) $d \imath$ - is in complementary distribution with the negative prefix. The interaction of the $d t$ - element with what are modal morphemes leads Thackston $(2006 \mathrm{a}, 4)$ to label both $d \imath$ - and $b \imath$ - as 'modal prefixes'.

In short, the interaction with negation and subjunctive morphology, which is external to the predicate $(\mathrm{VP} / \mathrm{AspP})$, supports the conclusion that the $d \imath^{-}\left(d_{2}\right)$ morphology is introduced when the basic shape of the predicate, either VP or AspP, is defined. Therefore the internal structure of the verb in (62) is to be revised to (64a). Correspondingly the structure of the verb in (59) is outlined in (64b). We leave the categorial status of $d \imath^{-}\left(d_{2-}\right)$ open, pending clarification of the exact nature of both its aspectual contribution and its interactions with modality. From an interpretive point of view recall that in footnote 7 , we suggested that what we call perfect here may not really be an exponent of perfective aspect, e.g., Cinque's

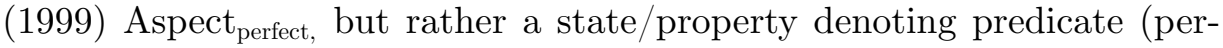
haps neutral aspect if Nash 2014 is correct). This should go some way towards easing the potential clash with the specifications of $d v^{-}\left(d_{2}-\right)$. The matter awaits further study; we note that placements of clitics in Sorani (section 4.3) is compatible with a different status for (the equivalent of) $d \imath^{-}\left(d \jmath^{-}\right)$and for other verb morphology.

(64) a. [də [Asp $[\mathrm{v}$ bin] $\mathrm{mm}]] \quad$ cf. $(62)$
b. $[$ dı $[\mathrm{V}$ krr $][$

\subsection{Sorani Kurdish}

In Sorani Kurdish (Thackston 2006b, cf. Dabir-Moghaddam 2012) both lexical DPs and full pronouns lack case inflections; yet an ergativity split is still visible in this language, in the agreement inflections associated with the verb and in the clitic system. As noted by Thackston, the latter have a distinctive morphological shape $(-m /-t /-i /-m a n /-y a n /-t a n)$ coinciding with that of possessive clitics within DPs, illustrated in (65). Based on their occurrence in (65) we will call these forms oblique clitics. ${ }^{27}$

27 The labels (M) and (S) specify the data from our Mariwan informant and those from our Sanandaj informant respectively. 
(65) ktjeb-akæ-i/-m/-n

book-DEF-3SG/-1SG/-3PL

'his/her/my/their-book'

In progressive/imperfective sentences, the verb inflection agrees with the external argument of transitives, as in $(66 \mathrm{a}-\mathrm{c})$ and with the sole argument of intransitives, as in (66d), reproducing the situation analysed for Kurmanji in (62). The oblique clitics in $(66 \mathrm{a}-\mathrm{c})$ pick up the internal argument of transitives, reproducing again the situation of Kurmanji (62). In the examples in (66) the clitic seems to be placed immediately to the left of the verb stem, where it is preceded however by the $a-/ e$ - morphology, comparable to the $d \partial-$ morphology of Kurmanji in both meaning and distribution, cf. (64). In (66c) we also find an occurrence of the - $t$ clitic after a Preposition, which is consistent with its oblique status.
(66) a. kor-ak-æ a-i/-m/-t bin-et
boy-DEF-LKR PROGR-3SG/-1SG/-2SG see-3SG
'The boy sees him/me/you.'
b. ema e-i/a-t for-in
we PROGR-3SG/PROGR-2SG wash-1PL
'We are washing it/you.'
c. mən e-i a-m pe:-t (ou krasa)
I PROGR-3SG give-1SG to-2SG the shirt
'I am giving it to you (the shirt).'
d. korake a- $\chi \varepsilon w-e t$ the.boy PROG-sleep-3sG
'The boy is sleeping.'

In short, in progressive/imperfective sentences Sorani is aligned with Kurmanji and can be analysed along the same lines. In the perfect, oblique clitics lexicalize the external argument of transitives, as in $(67 \mathrm{a}-\mathrm{c})$, revealing the existence in Sorani of an ergative alignment parallel to that of Kurmanji. ${ }^{28}$ As expected, the verb inflection agrees with the internal argument of transitives, as for instance in $(67 \mathrm{~b})$, or with the sole argument of intransitives, as in (67e). Distributionally, the clitic appears before the verb stem; in the absence of an $a$ - $/ e$ - prefix, it encliticizes on the closest argument, in $(67 \mathrm{a}-\mathrm{b})$. There also appears to be a descriptive constraint

${ }^{28}$ Karimi (2013), working within an Appl framework, argues that the oblique clitic of the perfect corresponds to a high Appl head. 
against sentence-initial clitics or clitics attaching to the subject, forcing the clitic to follow the verb in, say, (67c).

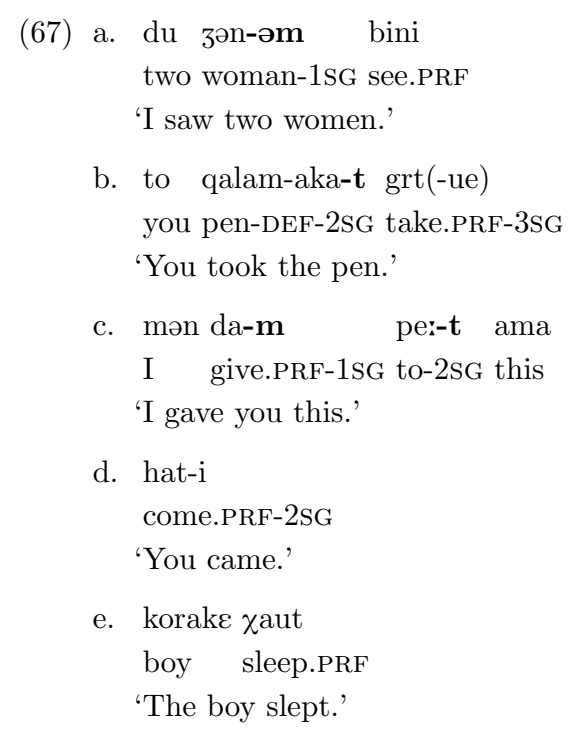

A further pattern emerges in transitive perfects, for our Sanandaj speaker, involving two oblique clitics, as in (68), one picking up the internal argument and the other the external argument. The realization of two obliques, one for the internal argument and one for the external one, creates a double oblique structure, also attested in varieties of Kurmanji (see footnote 26). In clusters of two object clitics, the internal argument clitic always precedes the external argument clitics (i.e., it is lower than it). ${ }^{29}$ The position of the clitics between the negation and the verb in (68b) further confirms the somewhat similar status that modal operators and the 'progressive' $a-/ e$ - prefix appear to enjoy in Kurdish.

29 The distribution of Sorani clitics seems comparable to that of Romance. Specifically, there are close correlates from Medieval Romance for the alternations between the preverbal positioning of the clitic in (67a-b) and its postverbal positioning (67c) - or the similar alternation in (64b) vs. (64a). Benincà (2006) suggests that "we have enclisis [i.e., postverbal position] when the Verb has moved to $\mathrm{C}$ and the preceding material is in [...] Topic", a description which suits our examples (67c) or (68a) if the subject is a Topic. The preverbal positioning is also consistent with that known from Romance languages since pronominal clitics are typically sequenced after negation clitics. The fact that they follow the $a-/ e$ - element in $(66 \mathrm{a}-\mathrm{c})$ suggests that the latter is to be understood as part of the clitic string in turn (in other words an aspectual particle of the clitic field). 
(68) a. ema di-t-man

we see.PRF.2SG.1PL

'We saw you.'

b. ema na-t-man-di

we NEG-2SG-1PL-see.PRF

'We did not see you.'

In short, in Sorani the perfect vs. non-perfect contrasts are restricted to oblique clitics, they are the same as in Kurmanji and admit of the same analysis. Non-perfect/imperfective sentences have an Asp layer of structure triggering nominative alignment and oblique internal arguments (clitics) of transitives. The simple structure of the predicate VP in the perfect triggers ergative alignment, and involves oblique external arguments (clitics) of transitives.

\section{Conclusions}

The so-called ergativity split between perfect and non-perfect (imperfective) sentences is observed both in languages with a specialized ergative case (e.g., Punjabi) and in languages with a more elementary case system (Kurdish). In present terms the ergativity split is due to the fact that perfects project an elementary VP predicate - which makes them more like APs or NPs; as a consequence, external arguments are not introduced directly on the predicative spine, but by means of an oblique case, i.e., an elementary predicate $(\subseteq)$ saying that the event is 'included by', 'located at' the argument (restricted to transitives in Kurdish). In a VP predicate furthermore the inflection picks up the internal argument (the closest merged argument in Kurdish), determining phi-feature identity with DP lexicalizations of the same argument ('agreement'). By contrast imperfectives have a complex organization (Asp-V) of the predicate/event, where the Asp head can introduce an argument (the external argument). The verb inflection picks up the external argument or the sole argument of intransitives, which appear in the direct case. It is eventually the internal argument that is introduced by an oblique elementary predicate/case (in Kurdish, or subject to DOM in Punjabi).

Much current formal literature adheres to what we may call the "new Chomskyan synthesis" heavily dependent on the "syntacticization of semantics" (Cinque \& Rizzi 2010) and on the Uniformity Hypothesis (Culicover \& Jackendoff 2006) - in a nutshell, on the existence of a precompiled Universal Grammar where complex sets of categories and their hierarchies 
are fixed cross-linguistically. In the present work we adopt a much more spare view of what is precompiled; the conceptual space of UG can be cut up by different categories in different languages, projecting different syntactic structures (compatible with semantic composition, i.e., Full Interpretation). Externalization is effected by the lexicon, and different lexicons define different grammars (Chomsky 1995).

\section{Acknowledgements}

The content of this article was presented under the title "On categories and hierarchies: Ergativity splits in Indo-Iranian languages" at the Budapest Conference on Projection and Representation in Syntactic Theory, in honour of Michael Brody, held between 13-14 April 2015. We are happy to present this work to Misi on the occasion of his 60th birthday. The research of M. Rita Manzini and Leonardo M. Savoia has benefited from PRIN 2012 funds, granted by the Italian MIUR; Ludovico Franco is supported by the Portuguese National Science Foundation, Fundação para a Ciência e a Tecnologia (FCT), with the research grant IF/00846/2013. We thank our informants, especially Miss Rajvir Kaur and her family, for their collaboration. The authors elaborated the article together; however, for Italian evaluation purposes, Ludovico Franco takes responsibility for sections 3.1, 3.2 and 4.3 .

\section{References}

Adger, David and Gillian Ramchand. 2005. Merge and Move: Wh-dependencies revisited. Linguistic Inquiry 36. 161-193.

Aissen, Joan. 2003. Differential object marking: Iconicity vs. economy. Natural Language \& Linguistic Theory 23. 435-483.

Aldridge, Edith. 2008. Generative approaches to ergativity. Language and Linguistic Compass 2. 966-995.

Alexiadou, Artemis. 2001. Functional structure in nominals: Nominalization and ergativity. Amsterdam \& Philadelphia: John Benjamins.

Anand, Pranav and Andrew Nevins. 2006. The locus of ergative case assignment: Evidence from scope. In Johns et al. (2006, 3-27).

Bailey, T. Grahame. 1904. Panjabi grammar. A brief grammar of Panjabi as spoken in the Wazirabad District. Lahore: Saaddi Panjabi Academy.

Baker, Mark. 2015. Case. Its principles and its parameters. Cambridge: Cambridge University Press.

Baker, Mark and Ümit Atlamaz. 2013. On the relationship of case to agreement in splitergative Kurmanji.

http://www.rci.rutgers.edu/ ua46/assets/pdf/mb_ua_draft.pdf

Baker, Mark and Nadya Vinokurova. 2010. Two modalities of case assignment in sakha. Natural Language \& Linguistic Theory 28. 593-642.

Beck, Sigrid and Kyle Johnson. 2004. Double objects again. Linguistic Inquiry 35. 97-124. 
Belvin, Robert and Marcel Den Dikken. 1997. There, happens, to, be, have. Lingua 101. 151-183.

Benincà, Paola. 2006. A detailed map of the left periphery of medieval Romance. In R. Zanuttini, H. Campos, E. Herburger and P. Portner (eds.) Crosslinguistic research in syntax and semantics. Negation, tense, and clausal architecture. Washington, DC: Georgetown University Press. 53-86.

Benveniste, Émile. 1966. Problèmes de linguistique générale 1. Paris: Gallimard.

Bhatia, Tej K. 1993. Punjabi: A cognitive-descriptive grammar. London: Routledge.

Bianchi, Valentina. 2006. On the syntax of personal arguments. Lingua 116. 2023-2067.

Béjar, Susana and Milan Rezac. 2009. Cyclic Agree. Linguistic Inquiry 40. 35-73.

Bobaljik, Jonathan. 1993. On ergativity and ergative unergatives. In C. Phillips (ed.) Papers on case and agreement II (MIT Working Papers in Linguistics 19). Cambridge, MA: MIT Press. 45-88.

Bobaljik, Jonathan David. 2008. Where's Phi? Agreement as a postsyntactic operation. In D. Harbour, D. Adger and S. Béjar (eds.) Phi theory: Phi-features across modules and interfaces. Oxford: Oxford University Press. 295-328.

Boneh, Nora and Ivy Sichel. 2010. Deconstructing possession. Natural Language \& Linguistic Theory 28. 1-40.

Butt, Miriam. 2006. The dative-ergative connection. In O. Bonami and P. C. Hofherr (eds.) Empirical issues in syntax and semantics 6. Paris: CNRS \& Université de Paris 7. 69-92. http://www.cssp.cnrs.fr/eiss6

Butt, Miriam and Tafseer Ahmed. 2011. The redevelopment of Indo-Aryan case systems from a lexical semantic perspective. Morphology 21. 545-572.

Butt, Miriam and Ashwini Deo. 2001. Ergativity in Indo-Aryan. Online KURDICA Newsletter for Kurdish Language and Studies, Volume 5. Revised version (2005) available at http://ling.uni-konstanz.de/pages/home/butt/main/papers/ia-erg.html.

Cardona, George. 1970. The indo-iranian construction mana (mama) krtam. Language 46. $1-12$.

Chomsky, Noam. 1995. The minimalist program. Cambridge, MA: MIT Press.

Chomsky, Noam. 2001. Derivation by phase. In M. Kenstowicz (ed.) Ken Hale: A life in language. Cambridge, MA: MIT Press. 1-52.

Cinque, Guglielmo. 1999. Adverbs and functional heads: A cross-linguistic perspective. Oxford: Oxford University Press.

Cinque, Guglielmo and Luigi Rizzi. 2010. The cartography of syntactic structures. In B. Heine and H. Narrog (eds.) The Oxford handbook of linguistic analysis. Oxford: Oxford University Press. 51-65.

Cocchi, Gloria. 1995. La selezione dell'ausiliare (Rivista di grammatica generativa: Serie monografica 12). Padova: Unipress.

Cocchi, Gloria. 1998. Ergativity in Romance languages. In O. Fullana and F. Roca (eds.) Studies on the syntax of central Romance languages. Girona: Universitat de Girona. 83-99.

Comrie, Bernard. 2005. Alignment of case marking. In M. Haspelmath, M. S. Dryer, D. Gil and B. Comrie (eds.) The world atlas of language structures. Oxford: Oxford University Press. 398-405.

Coon, Jessica. 2013. Aspects of split ergativity. Oxford: Oxford University Press. 
Coon, Jessica and Omer Preminger. 2012. Towards a unified account of person splits. In J. Choi, E. A. Hogue, J. Punske, D. Tat, J. Schertz and A. Trueman (eds.) Proceedings of the 29th West Coast Conference on Formal Linguistics. Somerville, MA: Cascadilla Proceedings Project. 310-318.

Culicover, Peter W. and Ray Jackendoff. 2006. The simpler syntax hypothesis. Trends in Cognitive Sciences 10. 413-418.

Dabir-Moghaddam, Mohammad. 2012. Linguistic typology: An Iranian perspective. Journal of Universal Language 13. 31-70.

D'Alessandro, Roberta and Ian Roberts. 2010. Past participle agreement in Abruzzese: Split auxiliary selection and the null-subject parameter. Natural Language \& Linguistic Theory 28. 41-72.

Déchaine, Rose-Marie, Raphaël Girard, Calisto Mudzingwa and Martina Wiltschko. 2014. The internal syntax of Shona class prefixes. Language Sciences 43. 18-46.

DeLancey, Scott. 1981. An interpretation of split ergativity and related patterns. Language 57. $626-657$.

Deo, Ashwini and Devyani Sharma. 2006. Typological variation in the ergative morphology of Indo-Aryan languages. Linguistic Typology 10. 369-418.

Dixon, Robert M. W. 1979. Ergativity. Language 55. 59-138.

Dorleijn, Margreet. 1996. The decay of ergativity in Kurmanci. Language internal or contact induced? Tilburg: Tilburg University Press.

Fillmore, Charles J. 1968. The case for case. In E. Bach and R. T. Harms (eds.) Universals in linguistic theory. New York: Holt, Rinehart and Winston. 1-88.

Franco, Ludovico, M. Rita Manzini and Leonardo M. Savoia. 2015. Linkers and agreement. The Linguistic Review 32. 277-332.

Franco, Ludovico, M. Rita Manzini and Leonardo M. Savoia. to appear. N morphology and its interpretation: The neuter in Central Italian varieties and its implications. Isogloss 1.

Freeze, Ray. 1992. Existentials and other locatives. Language 68. 553-595.

Giusti, Giuliana. 2008. Agreement and concord in nominal expressions. In C. de Cat and K. Demuth (eds.) The Bantu-Romance connection: A comparative investigation of verbal agreement, DPs and information structure. Amsterdam \& Philadelphia: John Benjamins. 201-237.

Haig, Geoffrey. 2008. Alignment change in Iranian languages: A construction grammar approach. Berlin \& New York: Mouton de Gruyter.

Haig, Geoffrey. 2011. Linker, relativizer, nominalizer, tense-particle: On the Ezafe in West Iranian. In F. H. Yap, K. Grunow-Hårsta and J. Wrona (eds.) Nominalization in Asian languages: Diachronic and typological perspectives. Amsterdam \& Philadelphia: John Benjamins. 363-390.

Hale, Kenneth and Samuel Jay Keyser. 1993. On argument structure and the lexical expression of syntactic relations. In K. Hale and S. J. Keyser (eds.) The view from building 20. Essays in linguistics in honor of Sylvain Bromberger. Cambridge, MA: MIT Press. 53-109.

Harley, Heidi. 2002. Possession and the double object construction. Linguistic Variation Yearbook 2. 29-68.

Harley, Heidi. 2013. External arguments and the Mirror Principle: On the distinctness of Voice and v. Lingua 125. 34-57. 
Harwood, William. 2015. Being progressive is just a phase: Celebrating the uniqueness of progressive aspect under a phase-based analysis. Natural Language \& Linguistic Theory 33. 523-573.

Higginbotham, James. 1985. On semantics. Linguistic Inquiry 16. 547-621.

Jelinek, Eloise. 1984. Empty categories, case and configurationality. Natural Language \& Linguistic Theory 2. 39-76.

Johns, A., D. Massam and J. Ndayiragije (eds.). 2006. Ergativity: Emerging issues. Dordrecht: Kluwer.

Johns, Alana. 1992. Deriving ergativity. Linguistic Inquiry 23. 57-87.

Karimi, Yadgar. 2013. Extending defective intervention effects. The Linguistic Review 30. $51-77$.

Kayne, Richard S. 1984. Connectedness and binary branching. Dordrecht: Foris.

Kayne, Richard S. 1993. Toward a modular theory of auxiliary selection. Studia Linguistica 47. 3-31.

Kayne, Richard S. 2010. Comparisons and contrasts. Oxford: Oxford University Press.

Keine, Stefan. 2010. Case and agreement from fringe to core: A minimalist approach. Berlin \& New York: Mouton de Gruyter.

Keine, Stefan and Gereon Müller. 2009. Differental argument encoding by impoverishment. In M. Richards and A. L. Malchukov (eds.) Scales (Linguistische Arbeitsberichte 86). Leipzig: University of Leipzig. 83-136.

Kihm, Alain. 2005. Noun class, gender and the lexicon/syntax/morphology interfaces: A comparative study of Niger-Congo and Romance languages. In G. Cinque and R. S. Kayne (eds.) The Oxford handbook of comparative syntax. Oxford: Oxford University Press. 459-512.

Laka, Itziar. 2006. Deriving split ergativity in the progressive: The case of Basque. In Johns et al. $(2006,173-196)$.

Lazard, Gilbert. 2005. Structures d'actances dans les langues irano-aryennes modernes. In D. Weber (ed.) Languages of Iran: Past and present. Iranian studies in memoriam David Neil MacKenzie. Wiesbaden: Harrassowitz. 81-93.

Lecoq, Pierre. 1989. Les dialectes caspiens et les dialectes du nord-ouest de l'Iran. In R. Schmitt (ed.) Compendium linguarum iranicarum. Wiesbaden: Ludwig Reichert. 296-314.

Legate, Julie Anne. 2008. Morphological and abstract case. Linguistic Inquiry 39. 55-101.

Legate, Julie Anne. 2014. Split ergativity based on nominal type. Lingua 148. 183-212.

Legendre, Geraldine. 2010. A formal typology of person-based auxiliary selection in ItaloRomance. In R. D'Alessandro, A. Ledgeway and I. Roberts (eds.) Syntactic variation: The dialects of Italy. Cambridge: Cambridge University Press. 86-101.

Lyons, John. 1967. A note on possessive, existential and locative sentences. Foundations on Language 3. 390-396.

Manzini, M. Rita and Ludovico Franco. to appear. Goal and DOM datives. Natural Language \& Linguistic Theory.

Manzini, M. Rita and Leonardo M. Savoia. 2005. I dialetti italiani e romanci. Morfosintassi generativa. Alessandria: Edizioni dell'Orso.

Manzini, M. Rita and Leonardo M. Savoia. 2007. A unification of morphology and syntax: Investigations into Romance and Albanian dialects. London: Routledge. 
Manzini, M. Rita and Leonardo M. Savoia. 2011a. Grammatical categories. Cambridge: Cambridge University Press.

Manzini, M. Rita and Leonardo M. Savoia. 2011b. Reducing 'case' to 'agreement': Nominal inflections in the Geg Albanian variety of Shkodër. Linguistic Variation 11. 76-120.

Manzini, M. Rita and Leonardo M. Savoia. 2014a. From latin to Romance: Case loss and preservation in pronominal systems. Probus 26. 217-248.

Manzini, M. Rita and Leonardo M. Savoia. 2014b. Person splits in the case systems of Geg Albanian (Shkodër) and Arbëresh (Greci). Studi italiani di linguistica teorica e applicata (SILTA) 43. 7-42.

Marantz, Alec. 1991. Case and licensing. In G. F. Westphal, B. Ao and H.-R. Chae (eds.) ESCOL '91: Proceedings of the Eighth Eastern States Conference on Linguistics. Columbus, OH: Ohio State University. 234-253.

Massam, Diane. 2006. Neither absolutive nor ergative is nominative or accusative. In Johns et al. $(2006,27-46)$.

Mohanan, Tara. 1994. Case OCP in Hindi. In M. Butt, T. H. King and G. Ramchand (eds.) Theoretical perspectives on word order issues in South Asian languages. Stanford, CA: CSLI Publications. 185-216.

Montaut, Annie. 2004. Oblique main arguments in Hindi/Urdu as localizing predications. Questioning the category of subject. In P. Bhaskararao and K. V. Subbarao (eds.) Non nominative subjects. Amsterdam \& Philadelphia: John Benjamins. 33-56.

Moravcsik, Edith A. 1978. Agreement. In J. H. Greenberg (ed.) Universals of human language. Stanford, CA: Stanford University Press. 331-373.

Nash, Léa. 1995. Portée argumentale et marquage casuel dans les langues SOV et dans les langues ergatives: l'example du géorgien. Doctoral dissertation. Université de Paris VIII.

Nash, Léa. 1997. La partition personnelle dans les langues ergatives. In A. Zribi-Hertz (ed.) Les pronoms: morphologie, syntaxe et typologie. Saint-Denis: Presses Universitaires de Vincennes. 129-150 PAGES??

Nash, Léa. 2014. The structural source of split ergativity and ergative case in Georgian. Manuscript. Université de Paris VIII.

Nevins, Andrew. 2011. Multiple agree with clitics: Person complementarity vs. omnivorous number. Natural Language \& Linguistic Theory 29. 939-971.

Paul, Daniel. 2011. A comparative dialectal description of Iranian Taleshi. Doctoral dissertation. University of Manchester.

Pesetsky, David. 1995. Zero syntax: Experiencers and cascades. Cambridge, MA: MIT Press.

Philip, Joy Naomi. 2012. Subordinating and coordinating linkers. Doctoral dissertation. UCL.

Plank, Frans (ed.). 1984. Objects: Towards a theory of grammatical relations. London: Academic Press.

Preminger, Omer. 2014. Agreement and its failures. Cambridge, MA: MIT Press.

Pylkkänen, Liina. 2008. Introducing arguments. Cambridge, MA: MIT Press.

Ramchand, Gillian and Peter Svenonius. 2008. Mapping a parochial lexicon onto a universal semantics. In T. Biberauer (ed.) The limits of syntactic variation. Amsterdam \& Philadelphia: John Benjamins. 219-245. 
Ramchand, Gillian and Peter Svenonius. 2014. Deriving the functional hierarchy. Language Sciences 46. 152-174.

Rizzi, Luigi. 1982. Issues in Italian syntax. Dordrecht: Foris.

Rizzi, Luigi. 1990. Relativized minimality. MIT Press: Cambridge, MA.

Schikowski, Robert. 2013. Object-conditioned differential marking in Chintang and Nepali. Doctoral dissertation. University of Zurich.

Smith, Carlota S. 1991. The parameter of aspect. Dordrecht: Kluwer.

Svenonius, Peter. 2006. The emergence of axial parts. Nordlyd Troms $\varnothing$ Working Papers on Language \& Linguistics 33. 1-22.

Thackston, Wheeler M. 2006a. Kurmanji Kurdish: A reference grammar with selected readings. Manuscript. Harvard University.

Thackston, Wheeler M. 2006b. Sorani Kurdish: A reference grammar with selected readings. Manuscript. Harvard University.

Verbeke, Saartje. 2013. Alignment and ergativity in New Indo-Aryan languages. Berlin \& New York: Mouton de Gruyter.

Verbeke, Saartje and Ludovic de Cuypere. 2009. The rise of ergativity in Hindi. Assessing the role of grammaticalization. Folia Linguistica (Acta Societatis Linguistica Europaeae) 30. 367-390.

Vergnaud, Jean-Roger. 2008. Letter to Noam Chomsky and Howard Lasnik on "Filters and Control". In R. Freidin, C. P. Otero and M. L. Zubizarreta (eds.) Foundational issues in linguistic theory. Essays in honor of Jean-Roger Vergnaud. Cambridge, MA: MIT Press. 3-15.

Woolford, Ellen. 1997. Four-way case systems: Ergative, nominative, objective and accusative. Natural Language \& Linguistic Theory 15. 181-227. 